\title{
Redescriptions and reestablishments of some species belonging to the genus Prionospio (Polychaeta, Spionidae) and descriptions of three new species
}

\author{
V. H. Delgado-Blas
}

Received: 18 April 2013/Revised: 9 October 2013/Accepted: 10 October 2013/Published online: 27 October 2013

(C) Springer-Verlag Berlin Heidelberg and AWI 2013

\begin{abstract}
Available type material of Prionospio heterobranchia Moore, 1907, P. (Prionospio) texana Hartman, 1951, P. spongicola Wesenberg-Lund, 1958 and $P$. (P.) newportensis Reish, 1959, as well as newly collected material from the Southern Gulf of Mexico and Chetumal Bay in the Caribbean Sea, was examined. Several important differences were found between P. heterobranchia, P. (Prionospio) texana, $P$. spongicola and $P$. (P.) newportensis, and as a result, these three species are removed from synonymy with $P$. heterobranchia Moore, 1907, and redescribed and reinstated as valid species. In addition, three new species were identified and described: $P$. caribensis sp. nov., $P$. rosariae sp. nov. and $P$.jamaicensis sp. nov. A key to all species of Prionospio with five pairs of branchiae is provided.
\end{abstract}

Keywords Taxonomy · Morphology · Polychaeta ·

Spionidae $\cdot$ Prionospio

\section{Introduction}

Prionospio was established by Malmgren (1867) to group all species of Spionidae that have 4 pairs of branchiae from chaetiger 2, the first and fourth pair pinnate, the second and third pair apinnate, with $P$. steenstrupi as the type species. With the discovery of new species, the diagnosis of the genus was widened to include species with different branchial shapes and arrangements. Variability has thus

Communicated by H.-D. Franke.

V. H. Delgado-Blas ( $₫)$

División de Ciencias e Ingeniería, Universidad de Quintana Roo,

77010 Chetumal, Quintana Roo, Mexico

e-mail: blas@uqroo.mx; vhdblas@hotmail.com increased, making Prionospio a very heterogeneous genus with over 78 species and including species with branchiae from chaetigers 1,2 and 3. As a result, several authors have suggested that some of the species should be reclassified into new genera and/or subgenera (Foster 1971; Blake and Kudenov 1978; Maciolek 1985; Wilson 1990).

In the most recent revision, Maciolek (1985) considered that species in the subgenus Prionospio are those with four or five pairs of branchiae, of which the first and fourth pairs or the first, fourth and fifth pairs are pinnate, and the second and third pairs are apinnate. Within this subgenus, all species having the same branchial formula as $P$. steenstrupi form the so-called steenstrupi-group. To date, 36 Prionospio species are recognized within this group (Sigvaldadóttir and Mackie 1993; Blake 1996; Sigvaldadóttir 1997; Zhou and Li 2009): 35 species with four pairs of branchiae and one species with five pairs of branchiae. In American waters, two further species and two subspecies have five pairs of branchiae: P. heterobranchia Moore, 1907 from Woods Hole, Massachusetts, USA, P. heterobranchia texana Hartman, 1951 from Turtle Bayou, Aransas Bay, Texas, P. spongicola Wesenberg-Lund, 1958 from the West Indies and P. heterobranchia newportensis Reish, 1959 from Southern California. However, the last three taxa were synonymized with $P$. heterobranchia Moore, 1907 by Foster (1971).

In this study, I examined type and non-type material of $P$. heterobranchia, $P$. heterobranchia texana, $P$. spongicola, and $P$. heterobranchia newportensis, as well as other species previously not described from the Grand Caribbean region. Important differences between these species were identified and each should be recognized as a distinct species: $P$. texana, $P$. spongicola, and $P$. newportensis. In addition, three new species were recognized and described from the Grand Caribbean region. 


\section{Materials and methods}

The material was collected off the Mexican Caribbean coast: Chetumal Bay, Nichupte, Cancun, Hualaxtoc, Mahahual, Holbox Island, Santa Cecilia, and the Indio River. Samples were passed through 0.5 and $1 \mathrm{~mm}$ sieves and fixed in $10 \%$ formalin. Samples were subsequently washed, sorted under a stereomicroscope and preserved in $70 \%$ ethanol. In order to observe some of the characters, specimens were dipped first into water and then into methyl green solution for staining. The colouration fades quickly when specimens are returned to the alcohol solution. Drawings were made with a camera lucida. Specimens were measured with a millimetre rule; the body width refers to the maximum postbranchial body width (includes parapodia but not chaetae, at about chaetiger 8).

Type and some non-type material were obtained from the collections housed in The Natural History Museum (BMNH), London, UK; the Allan Hancock Foundation Polychaete Collection at the Natural History Museum of Los Angeles County (LACMNH-AHF), Los Angeles, USA; the National Museum of Natural History (USNM), Washington, DC, USA; the Academy of Natural Sciences of Philadelphia (ANSP), Philadelphia, USA; and El Colegio de la Frontera Sur (ECOSUR), Chetumal, Mexico.

The new material has been deposited at ECOSUR, LACMNH-AHF, and USNM.

\section{Systematic section}

\section{Spionidae Grube, 1850 \\ Prionospio Malmgren, 1867 \\ Type species: Prionospio steenstrupi Malmgren, 1867 \\ Prionospio heterobranchia Moore, 1907}

Figure 1a-1

Prionospio heterobranchia Moore (1907: 195-197), plate 15, figs. 1-6. Foster (1971:90) (in part).

Prionospio (Prionospio) heterobranchia. Maciolek 1985: 341-343, fig. 5.

Material examined MASSACHUSETTS: August 4, 1902, muddy bottom of Eel Pond, Woods Hole, holotype (ANSP 850); Quisset Harbor, Woods Hole region, low tide mark, July 1957, coll. Mildred Campbell, 1 specimen (USNM 28962); Vineyard Sound, United States Fish Commission 1881, Little Harbor, 25 July 1881, 1 specimen (USNM 14466); Vineyard Sound, $41^{\circ} 32^{\prime} 35^{\prime \prime} \mathrm{N}, 70^{\circ} 54^{\prime} 44^{\prime \prime} \mathrm{W}$, coll. United States Fish Commission, 3 Aug 1882, 1 specimen, (USNM 45171); Barnstable Harbor, Cape Cod, mud flats, 29 July 1957, coll. Cambell, 1 specimen (USNM 28961); CONNECTICUT: east of Noank, Univ. Conn., 25 September 1962, Sta. 18 B, 6 specimens (USNM 67702).
Description Holotype incomplete, $22 \mathrm{~mm}$ long for 45 chaetigers, $1.0 \mathrm{~mm}$ wide. Non-type material shorter; 6-14.5 mm long for 46-69 chaetigers, $0.25-0.9 \mathrm{~mm}$ wide. Colour in alcohol dark brown.

Prostomium triangular, broadly rounded anteriorly (Fig. 1a); posteriorly tapered; with long, narrow caruncle beginning just after the posterior eyes (Fig. 1a), becoming more prominent and extending to the posterior edge of chaetiger 2. Two pairs of black, cup-shaped eyes; anterior pair small, set wide apart; posterior pair large and elongated (holotype with one pair of dark eyes), situated more closely together on the sides of the caruncle and between the bases of the palps (Fig. 1a). Palps lost. Peristomium short (Fig. 1b), collar-like, surrounding the prostomium, fused dorsally with small, rounded notopodial lamellae of chaetiger 1 (Fig. 1b, c). Neuropodial postchaetal lamellae of chaetiger 1 small, rounded (Fig. 1b), much smaller than half the size of the notopodial lamella.

Five pairs of short branchiae present on chaetigers 2-6 (Fig. 1a, b); first pair longest and thickest (Fig. 1c), sometimes first and fifth pairs equal in length. Pairs 1, 4 and 5 with long, dense digitiform pinnules on posterior face, and long naked, smooth distal tips; pair 5 with longest naked distal tips; distribution of the pinnules on these three pairs similar; the central stem of branchial pairs 1 and 5 pinnate and elongate, triangular on pair 4. Pairs 2 and 3 apinnate, densely ciliated laterally, triangular, wide, with short sharp tips; subequal in length, shorter than pinnate pairs, but slightly longer than notopodial lamellae (Fig. 1a-c).

Notopodial postchaetal lamellae of chaetigers 2-5 foliaceous with wide bases (Fig. 1b), distal halves narrow and elongate; largest on chaetigers 3-4 with sharp tips (Fig. 1b); lamellae on chaetigers 6-7 subtriangular with blunt tips (Fig. 1c). Subsequent notopodial lamellae rounded (Fig. 1d), connected by ridges or dorsal folds on postbranchial chaetigers 7-19 (Fig. 1e), more conspicuous on chaetigers 7-11; notopodial lamellae small, rounded in far posterior chaetigers (Fig. 1f). Ventral and dorsal edges of notopodial and neuropodial lamellae touching on chaetigers 3-5 (Fig. 1b). Notopodial prechaetal lamellae very large in branchial region, basally fused with notopodial postchaetal lamellae (Fig. 1c), prechaetal lamellae of chaetiger 13 and subsequent lamellae progressively decreasing in size, split and becoming rounder and smaller (Fig. 1d), short on far posterior chaetigers.

Neuropodial postchaetal lamellae rounded throughout (Fig. 1b, d), far posterior lamellae smallest (Fig. 1f). Neuropodial prechaetal lamellae large in branchial region, but rudimentary in far posterior chaetigers. Interparapodial pouches lacking.

Chaetae of anterior chaetigers granulated, with lightly striated capillaries; notopodial chaetae unilimbate (Fig. 1g) 

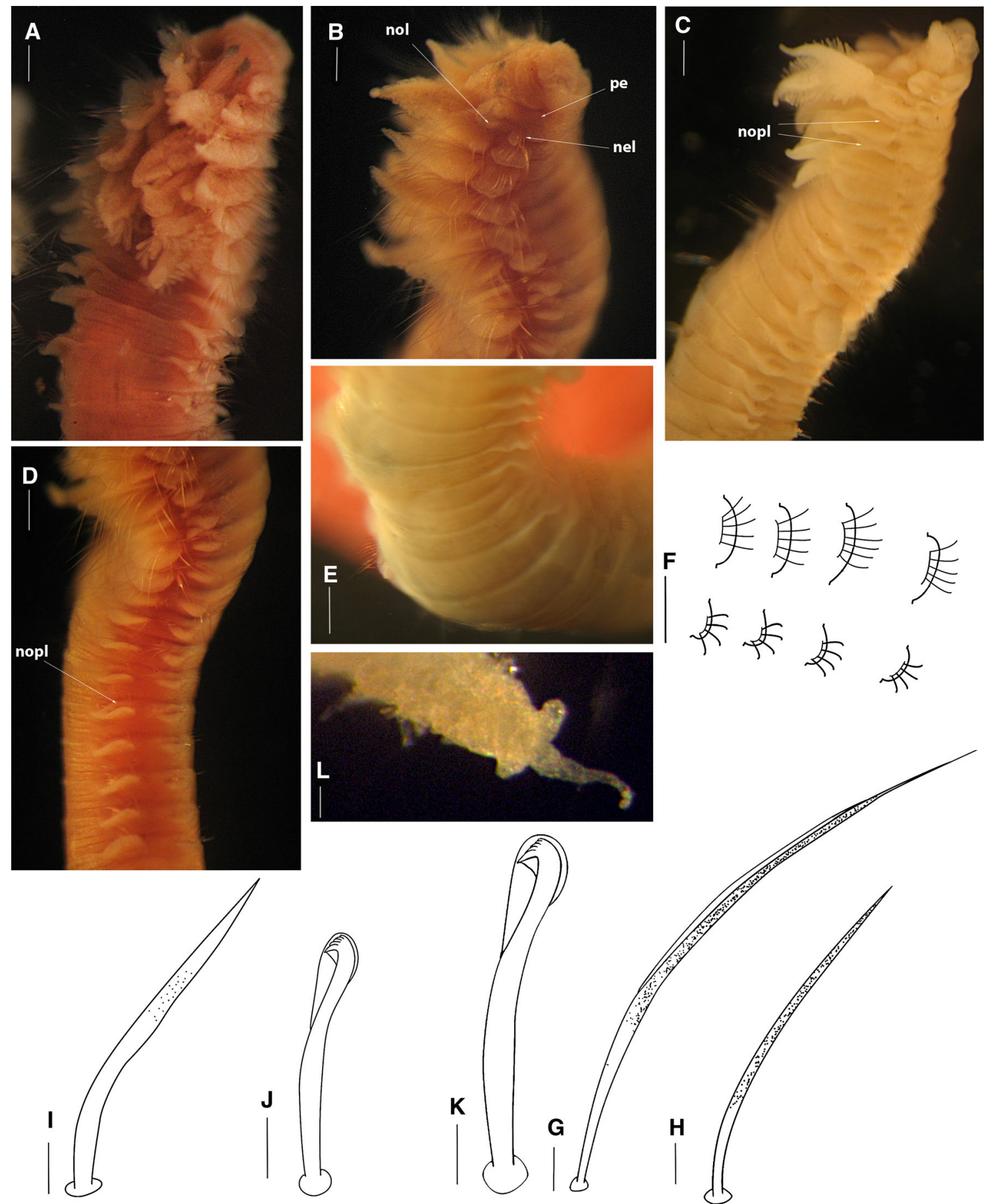

Fig. 1 Prionospio heterobranchia Moore, 1907. Non-type (USNM 28961: a, b, d, f, g-k; USNM 14466: c, e; USNM 67702: l): a Anterior region, dorsal-lateral view. b Anterior region, lateral view. c Anterior segments, dorsal-lateral view. d Anterior segments. e Dorsal ridges on chaetigers 7-14. f Posterior segments. g Anterior

arranged in three (Massachusetts material) or two (Connecticut material) rows, neuropodial chaetae alimbate (Fig. 1h) in two rows; with the posterior row longest; notochaetae from chaetiger 15 granulated, arranged in one row, and neurochaetae from about chaetiger 13 also

notopodial chaeta. h Anterior neuropodial chaeta. i Sabre chaeta. j Neuropodial hooded hook. k Notopodial hooded hook. I Pygidium, dorsal view. pe Peristomium, nol Notopodial lamellae, nopl Notopodial prechaetal lamellae (Scale bars $\mathbf{a}-\mathbf{f}, \mathbf{l} 30 \mu \mathrm{m}, \mathbf{g}-\mathbf{k} 5 \mu \mathrm{m}$ )

arranged in one row, dorsal chaetae very long and ventral chaetae short; posterior notopodia with thinner and shorter chaetae than middle notopodia. Sabre chaetae from chaetigers 13-15 (holotype: 15), up to two per fascicle, each chaeta lightly granulated and without a sheath (Fig. 1i). 
Neuropodial hooded hooks (Fig. 1j) from chaetigers 13-15 (holotype: 15), up to seven per fascicle, accompanied by up to three thin capillaries. Notopodial hooded hooks (Fig. 1k) longer, slender and fewer per fascicle, from chaetigers 32-40 (holotype: 40), up to three per fascicle, accompanied by up to four thin capillaries; all hooks with four pairs of small teeth above main tooth and conspicuous secondary hood (Fig. 1j, k).

Pygidium with one long thin median cirrus and two shorter lateral lobes (Fig. 11).

Remarks The original description presented by Moore (1907) was incorrect in a number of aspects (e.g., the first neuropodial lamellae apparently with a slender cirrus like process on the ventral border, hooded hooks with 3 or 4 small teeth above the main tooth). I reexamined the $P$. heterobranchia holotype and observed rounded neuropodial lamellae on chaetiger 2 , hooded hooks with 4 pairs of teeth above the main tooth and hooks with secondary hoods. The first pair of eyes, however, could not be seen, possibly due to the poor condition of the holotype.

Foster (1971) gave a description of $P$. heterobranchia based on the type material of $P$. spongicola, P. heterobranchia texana and specimens from Massachusetts, Rhode Island, Virginia, Florida and the Bahamas. However, according to the reexamination of $P$. heterobranchia in this paper of specimens from Massachusetts and the redescriptions of $P$. spongicola and $P$. texana, it is probable that Foster's (1971) collection contains more than one species. Thus, the specimens from Massachusetts examined by Foster may be $P$. heterobranchia, but the specimens from Florida should be revised in order to verify their identity.

The description of this species here agrees with that of Maciolek (1985), but with differences in the distribution of the sabre chaetae and neuropodial hooded hooks. However, Maciolek made no mention in her description of the holotype of $P$. heterobranchia.

Distribution Massachusetts, Connecticut, Rhode Island, Virginia, N Carolina; low tide mark and mud flats, 3-3.5 m.

Prionospio caribensis sp. nov.

(Figure 2a-j)

Material examined Caribbean Sea: Nichupté, E3MIT1, Cancún, Quintana Roo, $21^{\circ} 02^{\prime} \mathrm{N}, 86^{\circ} 46^{\prime} \mathrm{W}$, Thalassia testudinum, 4 paratypes (ECOSUR-0162), coll. S. Jiménez and J. Oliva, 21 February 1988; Nichupté, E2MIT1, Cancún, Quintana Roo, 3 specimens (ECOSUR-P1430), coll. J. Oliva, 27 October 1987; Nichupté, Cancún, Quintana Roo, $21^{\circ} 02^{\prime} \mathrm{N}, 86^{\circ} 46^{\prime} \mathrm{W}$, holotype (USNM 1187919), coll. S. Jiménez and J. Oliva, 2 March 1988; Nichupté,
Cancún, Quintana Roo, 3 specimens (ECOSUR-P1431), coll. S. Jiménez and J. Oliva, 2 March 1988; Nichupté, E1M5T1, Cancún, Quintana Roo, 6 specimens (ECOSURP1419), coll. J. Oliva, 12 April 1988; Nichupté, E6M5T1, Cancún, Quintana Roo, 1 specimen (ECOSUR-P1424), 6 July 1988. Isla Holbox, Quintana Roo, $21^{\circ} 31^{\prime} 8^{\prime \prime} \mathrm{N}$, $87^{\circ} 22^{\prime} 26^{\prime \prime} \mathrm{W}, 1$ specimen (ECOSUR-P1427), 4 November 2002. Santa Cecilia, Quintana Roo, $20^{\circ} 13^{\prime} 88^{\prime \prime} \mathrm{N}$, $87^{\circ} 45^{\prime} 28^{\prime \prime} \mathrm{W}, 6$ specimens (ECOSUR-P1420), 4 November 1990. Faro Xcayal, Quintana Roo, $20^{\circ} 22^{\prime} 13^{\prime \prime} \mathrm{N}$, $87^{\circ} 45^{\prime} 09^{\prime \prime} \mathrm{W}, 2$ specimens (ECOSUR-P1416), 4 November 1990. Hualaxtoc, Quintana Roo, $19^{\circ} 38^{\prime} \mathrm{N}, 87^{\circ} 23^{\prime} \mathrm{W}, 3$ specimens (ECOSUR-P1415), coll. S. Jiménez and J. Oliva, 26 February 1986. Mahahual, Quintana Roo, $18^{\circ} 40^{\prime} 09^{\prime \prime} \mathrm{N}, 87^{\circ} 43^{\prime} 01^{\prime \prime} \mathrm{W}, 1$ specimen (ECOSUR-P1417), 3 October 1996; Mahahual, sand, Quintana Roo, $18^{\circ} 40^{\prime} 09^{\prime \prime} \mathrm{N}, 8^{\circ} 43^{\prime} 01^{\prime \prime} \mathrm{W}, 1$ specimen (ECOSUR-P1429), 18 March 2002. Río Indio, Quintana Roo, $18^{\circ} 54^{\prime} 15^{\prime \prime} \mathrm{N}$, $87^{\circ} 38^{\prime} 36^{\prime \prime} \mathrm{W}, 21$ specimens (ECOSUR-P1421), November 1990.

Description Holotype complete, $14 \mathrm{~mm}$ long for 67 chaetigers, $0.8 \mathrm{~mm}$ wide. Paratypes $11.5-15.0 \mathrm{~mm}$ long, 0.6-0.8 mm wide, with 49-70 chaetigers. Colour in alcohol opaque white. Prostomium bottle-shaped, rounded on anterior margin (Fig. 2a), posteriorly tapered, with narrow caruncle extending to the posterior edge of chaetiger 2, with large triangular nuchal organs on either side. Two pairs of subdermal eyes, arranged in a trapezoid: first pair brown to red, crescent-shaped; posterior pair black, oval and very large (Fig. 2a). Palps lost. Peristomium moderate, collar-like, surrounding the prostomium, fused dorsally with large rounded notopodial lamellae of chaetiger 1 (Fig. 2a), almost the same size as the neuropodial lamellae. Neuropodial postchaetal lamellae of chaetiger 1 large, rounded (Fig. 2a).

Five pairs of very long branchiae present on chaetigers 2-6; first pair longest and very thick (Fig. 2a), sometimes all branchiae the same size. Pairs 1, 4 and 5 with long and dense digitiform pinnules on the posterior face, with long, naked, smooth distal tips; fourth and fifth pairs thinner, the fourth pair with very short and the fifth pair with very long, naked tips (Fig. 2a). Pairs 2 and 3 apinnate, densely ciliated laterally, triangular, with short, tapered tips (Fig. 2a); subequal in length, generally shorter than pinnate pairs, but longer than the notopodial lamellae (Fig. 2a).

Notopodial postchaetal lamellae triangular, wider and rounded at base on chaetigers 2-6 (Fig. 2b); largest on chaetigers 3-5 with tapered tips; lamellae of chaetigers 7-9 subtriangular with blunt tips (Fig. 2c). Subsequent notopodial lamellae rounded, very small on far posterior chaetigers (Fig. 2d). Chaetigers 2-4 with the ventral and dorsal edges of the notopodial and neuropodial lamellae 


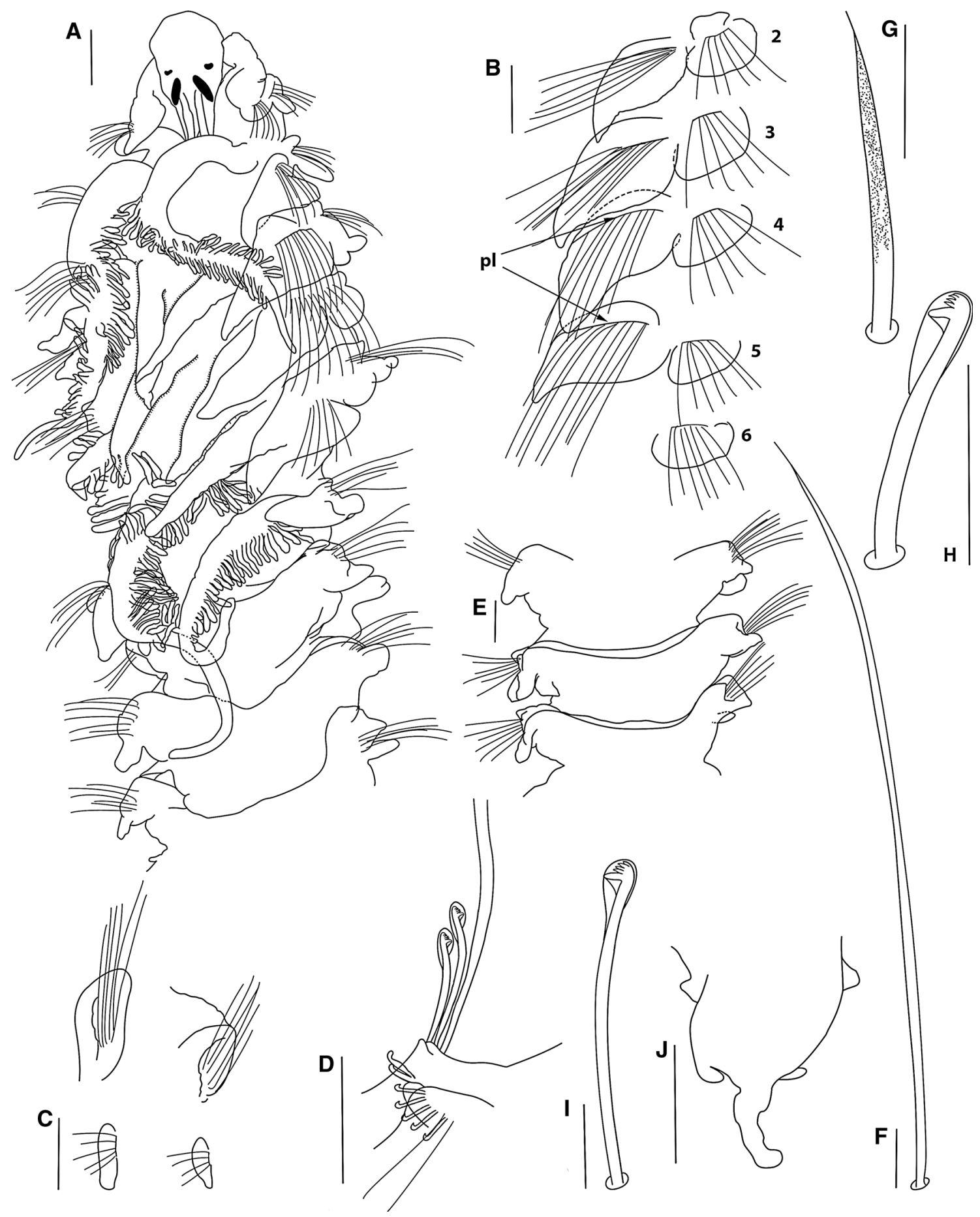

Fig. 2 Prionospio caribensis sp. nov., holotype (USNM 1187919): a Anterior region, dorsal-lateral view. b Parapodia of chaetigers 2-6. c Parapodium of chaetiger 8 (left)-9 (right), ventral view. d Parapodium of posterior chaetiger. e Dorsal ridges on chaetigers 7-9.

overlapping (Fig. 2b). Notopodial prechaetal lamellae very large in the branchial region, basally fused with the notopodial postchaetal lamellae (Fig. 2a, b), progressively decreasing in size after chaetiger 16, becoming smaller and more rounded on posterior chaetigers. Low dorsal ridges f Capillary chaeta of anterior chaetiger. $\mathbf{g}$ Sabre chaeta. $\mathbf{h}$ Neuropodial hooded hook. i Notopodial hooded hook. j Pygidium, dorsal view. Notopodial prechaetal lamellae: pl (Scale bars a $140 \mu \mathrm{m}, \mathbf{b}-\mathbf{e}$, j $30 \mu \mathrm{m}, \mathbf{f}-\mathbf{i} 5 \mu \mathrm{m})$

across the dorsum on chaetigers 7-15 (Fig. 2e), highest on chaetigers 10-13.

Neuropodial postchaetal lamellae rounded throughout, except the neuropodium of chaetiger 3 , which is square (Fig. 2b), smallest on far posterior chaetigers (Fig. 2d). 


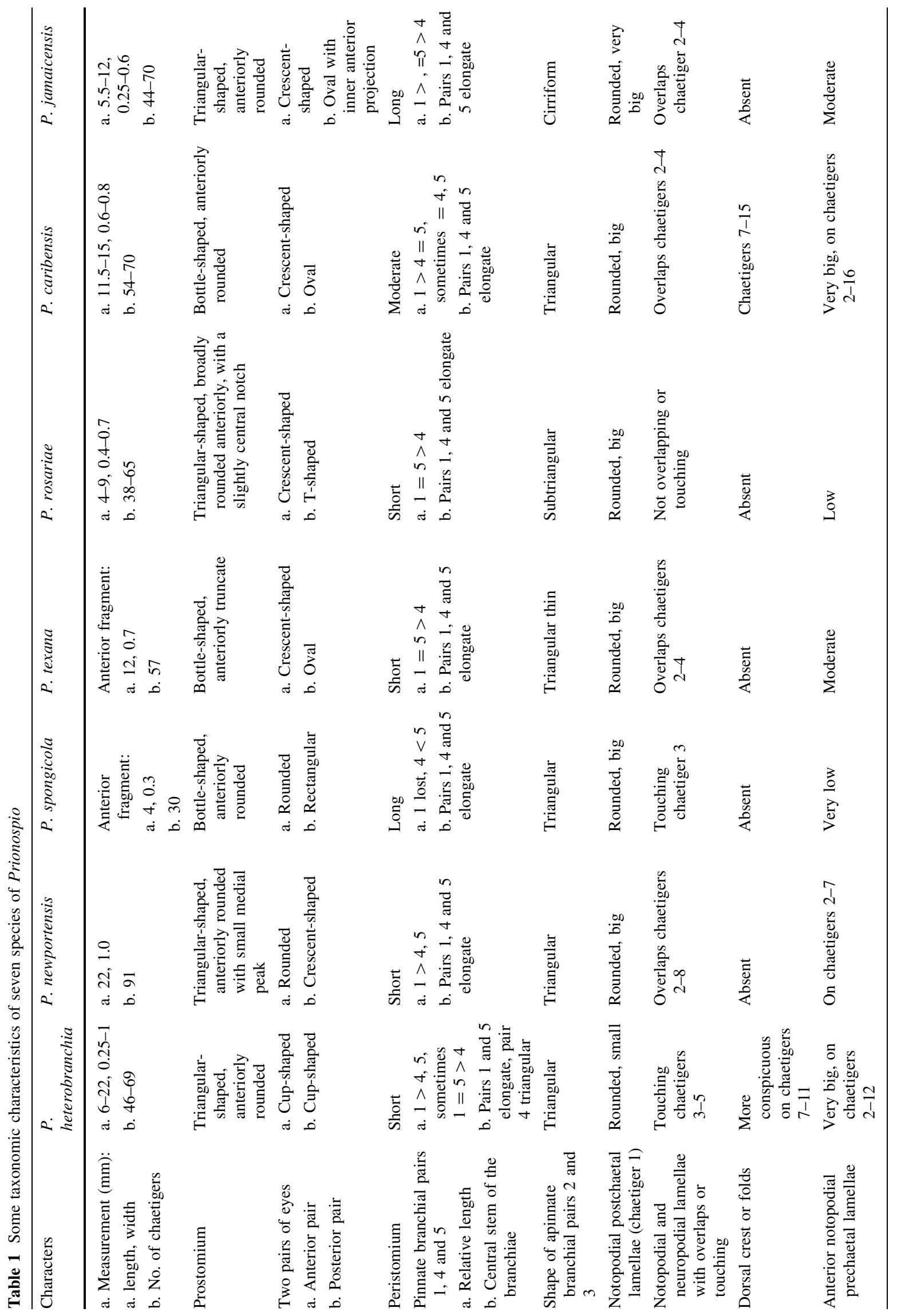




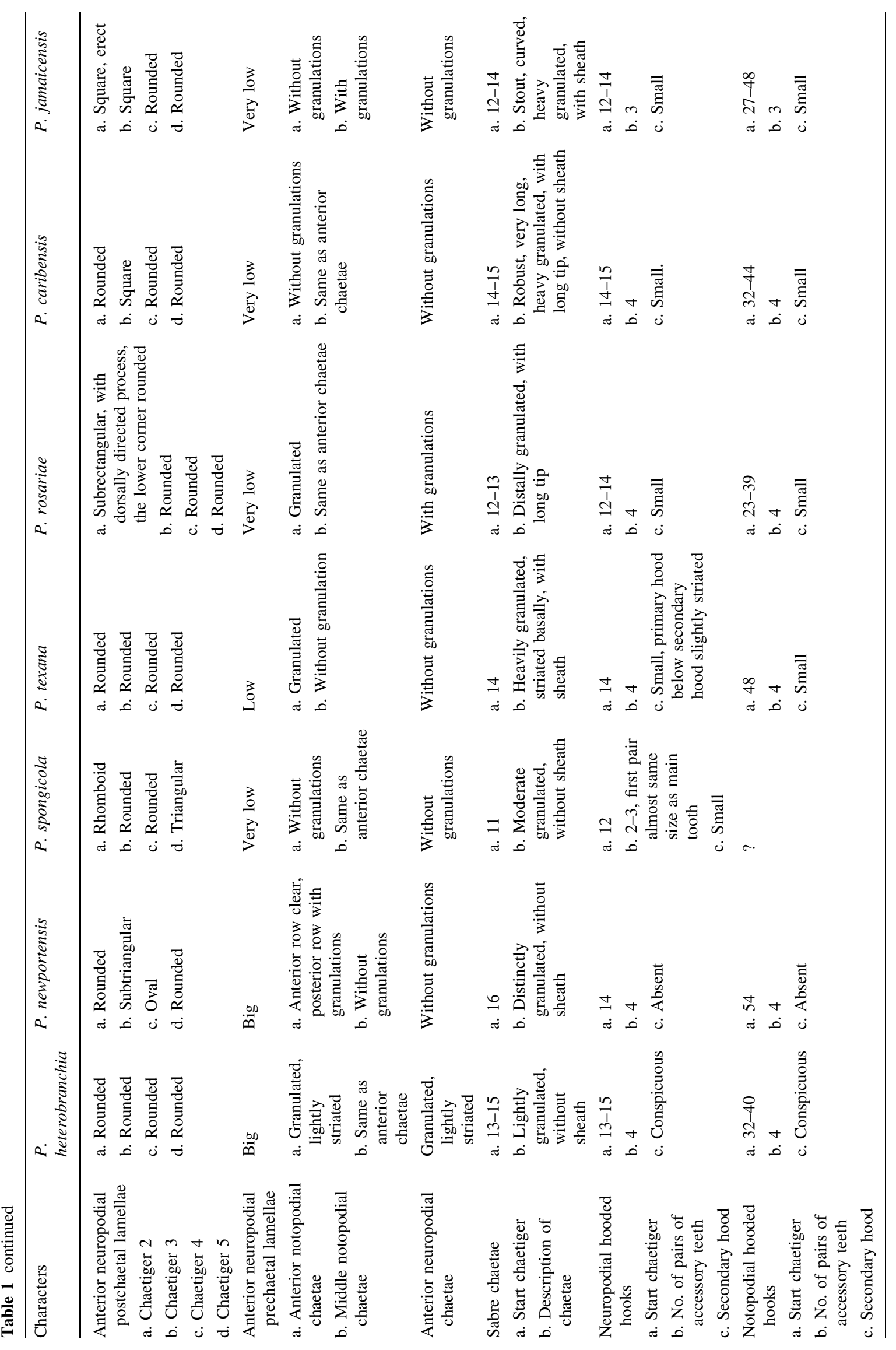


Prechaetal lamellae very small, rudimentary throughout. Interparapodial pouches lacking.

Anterior chaetae All capillaries unilimbate, thin, lacking granulations, with long capillary tips (Fig. 2f); notopodial and neuropodial capillaries of chaetiger 1 arranged in two rows, with short and thin chaetae, notopodial chaetae longer; from chaetiger 2 onwards arranged in two rows, anterior row shorter than posterior row; chaetae on middle and posterior notopodia arranged in one row, dorsal chaetae very long and ventral chaetae short. Sabre chaetae in neuropodia from chaetigers 14-15, one or two per fascicle, robust, very long, heavily granulated, with long tips but no sheaths (Fig. $2 \mathrm{~g}$ ). Neuropodial hooded hooks from chaetigers $14-15$, up to eight per fascicle, accompanied by up to three capillaries. Notopodial hooded hooks from chaetigers 32-44, up to four per fascicle, accompanied by capillaries; all hooks with four pairs of small teeth above the main tooth and a small secondary hood. Neuropodial hooks with a large principal hood (Fig. 2h), and notopodial hooks with small hoods (Fig. 2i).

Pygidium with one long dorsomedial cirrus and two short lateral cirri (Fig. 2j).

Remarks Prionospio caribensis is very similar to $P$. heterobranchia, in having dorsal folds on several postbranchial chaetigers, very large notopodial prechaetal lamellae fused with the notopodial postchaetal lamellae, neuropodial postchaetal lamellae of chaetigers 2, 4 and 5 rounded and notopodial and neuropodial hooded hooks with 4 pairs of teeth. Prionospio caribensis differs from $P$. heterobranchia in that the former has a bottle-shaped prostomium, a longer peristomium, a different eyes shape, longer noto- and neuropodial postchaetal lamellae on chaetiger 1, longer branchiae, the central stem of the fourth pair of branchiae elongate, chaetiger 3 with square neuropodial postchaetal lamellae, and thin capillary chaetae, lacking granulations. P. caribensis differs from the other Prionospio species examined in this study in that the first pair of branchiae are longer and thicker, and the sabre chaetae are more robust and longer, with very long tips. The differences between this new species from the other species examined can be appreciated from the key provided and Table 1 .

Distribution Caribbean Sea: Quintana Roo. Thalassia testudinum, sand.

Etymology The name refers to the fact that this species inhabits the Caribbean Sea.

Prionospio texana Hartman, 1951, new status

Figure $3 \mathrm{a}-\mathrm{h}$

Prionospio heterobranchia texana Hartman, 1951: 85.

Material examined Gulf of Mexico, USA: Texas, Aransas Bay, Turtle Bayou, from fine sand mixed with decaying vegetation, October 1950, coll. A.E. Hartman, holotype (LACM-AHF-POLY 0617).

Redescription Holotype incomplete, $12.0 \mathrm{~mm}$ long; consists of two fragments with 57 chaetigers, posterior region lacking, $0.7 \mathrm{~mm}$ wide. Colour in alcohol opaque white. Prostomium bottle-shaped, truncate on anterior margin (Fig. 3a); posteriorly tapered, with narrow caruncle extending to the posterior edge of chaetiger 2. Two pairs of subdermal eyes; arranged in a trapezoid; anterior pair black, crescent-shaped; posterior pair red-brown, very large, oval (Fig. 3a). Palps lost. Peristomium short, collarlike, surrounding prostomium, fused dorsally with large rounded notopodial lamellae on chaetiger 1 (Fig. 3a). Neuropodial postchaetal lamellae on chaetiger 1 small and rounded (Fig. 3a), which are much smaller than half that of the notopodial lamella.

Five pairs of very long, thin branchiae present on chaetigers 2-6; first and fifth pairs longest, twice the length of the other pairs; pairs 1, 4 and 5 with long, densely arranged digitiform pinnules on the posterior face, and with long, naked, smooth distal tips (Fig. 3a); the distribution of pinnules on these three pairs is similar, larger basally, but pair 5 with longer naked distal tips (Fig. 3a). Pairs 2 and 3 apinnate, thin, triangular, densely ciliated laterally and with sharply pointed tips; subequal in length, slightly longer than the notopodial lamellae but shorter than the pinnate pairs (Fig. 3a).

Notopodial postchaetal lamellae on chaetigers 2-4 erect, auricular (Fig. 3a); largest on chaetigers 3-4, with blunt tips; lamellae subtriangular on chaetigers 5-6 (Fig. 3a). Subsequent notopodial lamellae rounded (Fig. 3b), small on far posterior chaetigers. Notopodial and neuropodial lamellae of chaetigers 2-4 with overlapping ventral and dorsal edges. Notopodial prechaetal lamellae moderately sized in the branchial region, basally fused with the notopodial postchaetal lamellae (Fig. 3a); progressively decreasing in size from chaetiger 7 , becoming smaller and more rounded on posterior chaetigers. Dorsal crest or folds absent.

Neuropodial postchaetal lamellae rounded throughout (Fig. 3a, c), smallest on far posterior chaetigers (Fig. 3d). Prechaetal lamellae short, rudimentary throughout. Interparapodial pouches lacking.

All capillaries slender on anterior chaetigers; notochaetae granulated (Fig. 3e), but neurochaetae not granulated (Fig. 3f); notopodial and neuropodial capillaries of chaetiger 1 arranged in one row, with short, slender chaetae, notopodial chaetae longer. Notopodial capillaries of chaetigers 2-23 arranged in two rows, with anterior row shorter than posterior row; middle notopodia arranged in one row of chaetae, with dorsal chaetae very long and ventral chaetae short; posterior notopodia with more slender and shorter chaetae than middle notopodia. 
Fig. 3 Prionospio texana Hartman, 1951 holotype (LACM-AHF-POLY 0617):

a Anterior region, dorsal-lateral view. b Notopodium of chaetiger 17. $\mathbf{c}$ Neuropodium of chaetiger 8. d Neuropodium of chaetiger 16. e Anterior capillary notochaeta. f Anterior capillary neurochaeta. g Sabre chaeta. h Neuropodial hooded hook. i Notopodial hooded hook. (Scale bars a-d $50 \mu \mathrm{m}$, e-i $20 \mu \mathrm{m})$
A

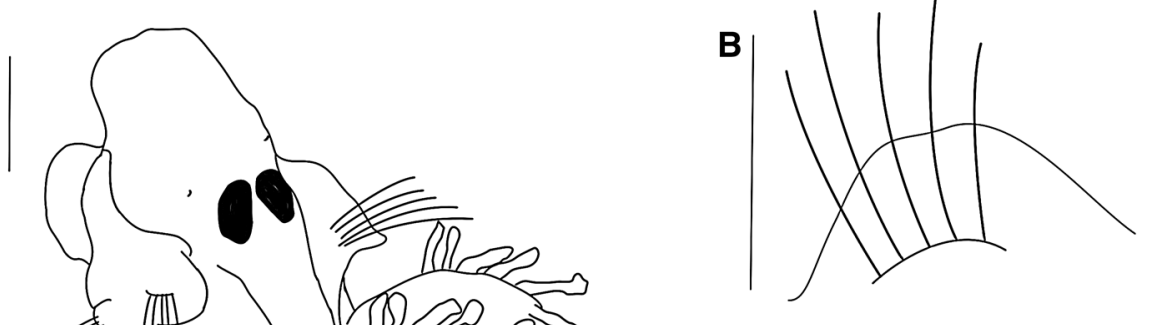

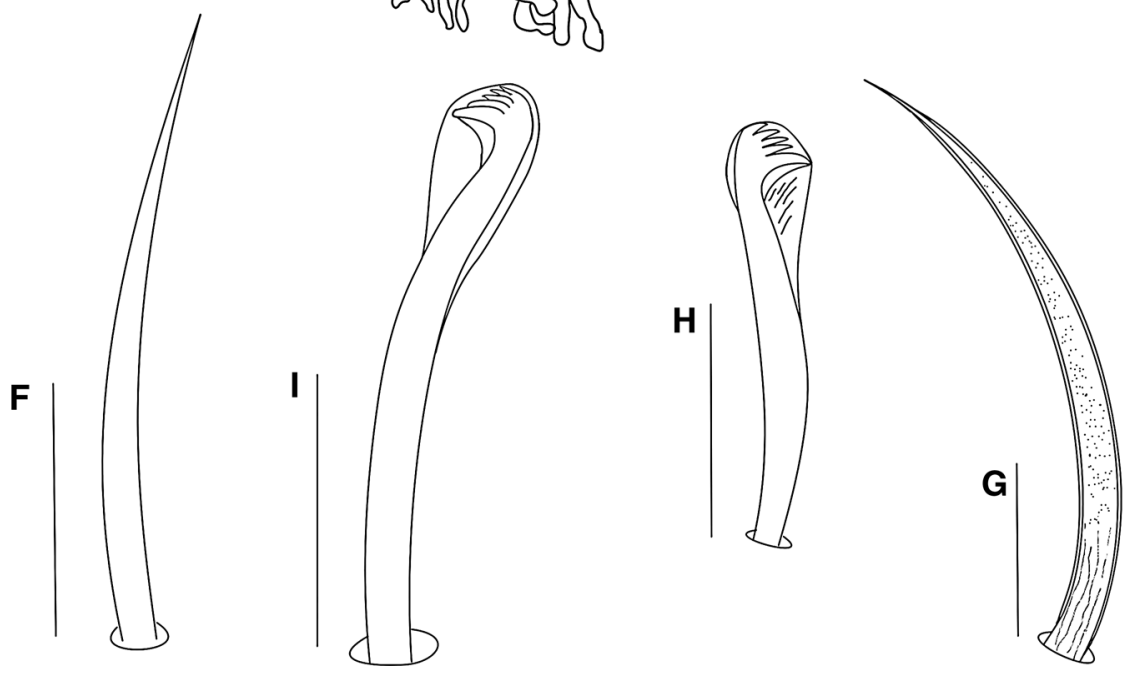

Neurochaetae arranged in two rows on chaetigers 2-13, with anterior row shorter than posterior row, chaetae of middle neuropodia with one row of chaetae; posterior neuropodia with one or two more slender, shorter chaetae.
Sabre chaetae from chaetiger 14, one or two per fascicle, stout, curved, heavily granulated, and striated basally, with sheaths (Fig. 3g). Neuropodial hooded hooks (Fig. 3h) from chaetiger 14, up to six per fascicle, accompanied by 


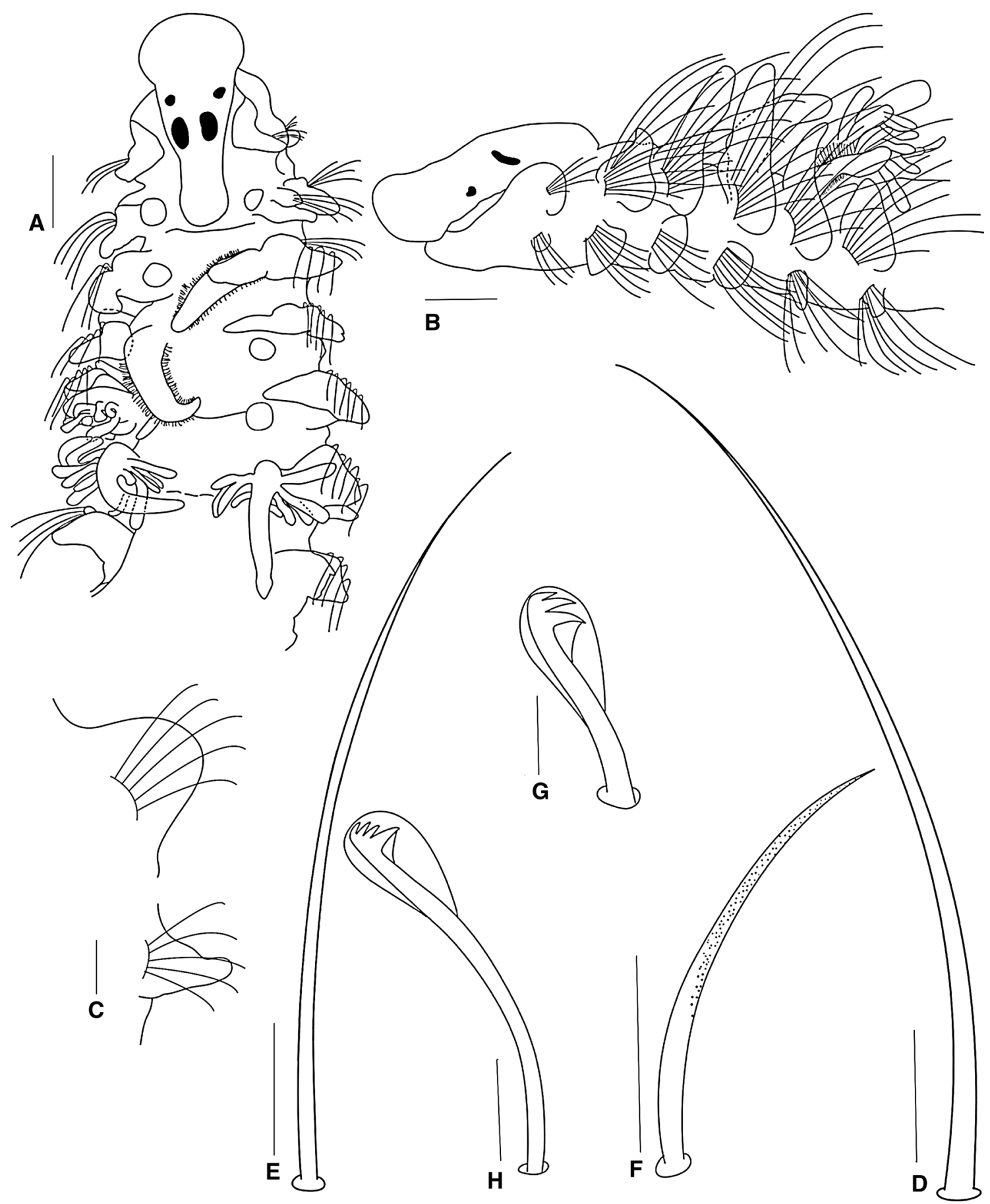

Fig. 4 Prionospio spongicola Wesenburg-Lund, 1958 holotype (BMNH 1958.1.27.1). a Anterior region, dorsal view. b Anterior region, lateral view. c Parapodium of posterior chaetiger of the fragment. d Capillary notochaeta of chaetiger 8. e Capillary

capillaries. Notopodial hooded hooks (Fig. 3i) from chaetiger 48 , up to two per fascicle, accompanied by up to seven capillaries; all hooks with four pairs of small teeth above the main tooth and small secondary hoods (Fig. 3h, i); primary hood of neuropodial hooks slightly striated below secondary hoods (Fig. 3h). neurochaeta of chaetiger 10. f Sabre chaeta of chaetiger 30 . g Neuropodial hooded hook from chaetiger 14. h Neuropodial hooded hook from chaetiger 30. (Scale bars a-b $100 \mu \mathrm{m}$, d-f $40 \mu \mathrm{m}$, g $10 \mu \mathrm{m}, \mathbf{c}, \mathbf{h} 20 \mu \mathrm{m})$

Remarks Foster (1971) placed this subspecies in synonymy with $P$. heterobranchia because of the variation she observed in the morphologies of different specimens within a single collection, including that of the stem species and both subspecies ( $P$. h. texana and $P . h$. newportensis), and also the fact that no other taxonomic differences could be 
found upon examination of the type material. In the present study, however, examination of the $P$. texana and $P$. heterobranchia holotypes revealed that they do, in fact, show morphological differences. $P$. texana definitely represents a distinct species and can be separated from $P$. heterobranchia on the basis of several characters.

$P$. texana differs from $P$. heterobranchia in that the former has larger notopodial postchaetal lamellae on chaetiger 1, does not have dorsal folds and has longer branchiae. In addition, the neuropodial prechaetal lamellae are short, all the anterior neurochaetae lack granulations, the sabre chaetae are heavily granulated and notopodial hooded hooks are present from chaetiger 48 .

Prionospio texana differs from the other Prionospio species examined in this study in that it has a bottle-shaped prostomium truncated on the anterior margin and neuropodial hooded hooks with slightly striated primary hoods. In addition, $P$. texana has granulated anterior notochaetae, but no granulations on the anterior neurochaetae, whereas the other species have anterior notopodial and neuropodial chaetae with or without granulations. The differences between this new species and the other species examined can be appreciated from the key provided and Table 1 .

Distribution Gulf of Mexico, Texas, Aransas Bay, Turtle Bayou, from fine sand mixed with decaying vegetation.

\section{Prionospio spongicola Wesenburg-Lund, 1958 reestablished \\ Figure 4a-h \\ Prionospio spongicola Wesenburg-Lund, 1958: 19, fig. 12.}

Material examined Trinidad, West Indies, Gasparee Cave on the Island of Gasparo Grande, Northwestern Atlantic, Sta 655, coll. P. Wageraar Hummelinch, 11 January 1955, holotype (BMNH-1958.1.27.1).

Redescription Holotype incomplete, $4.0 \mathrm{~mm}$ long for 30 chaetigers, $0.3 \mathrm{~mm}$ wide. Colour in alcohol opaque white.

Prostomium bottle-shaped, rounded anteriorly (Fig. 4a); posteriorly tapered with blunt caruncle extending to the anterior edge of chaetiger 2 (Fig. 4a). Two pairs of black subdermal eyes, arranged in a trapezoid; anterior pair rounded; posterior pair large, rectangular (Fig. 4a). Palps lost. Peristomium long, collar-like, surrounding prostomium, fused dorsally with large rounded notopodial lamellae on chaetiger 1 (Fig. 4b). Neuropodial postchaetal lamellae of chaetiger 1 very small, rounded (Fig. 4b), which are much smaller than half that of the notopodial lamella.

Five pairs of long branchiae present on chaetigers 2-6; first pair lost, fifth pair longest. Pairs 1 (original description), 4 and 5 with a few long digitiform pinnules (Fig. 4a). Pinnules on basal and middle regions of the branchiae thick, blunt and arranged along the posterior margins of the stems, those nearest the base being the longest; pair 4 with fewer and shorter digitiform pinnules than pair 5; branchiae with very long naked distal tips (Fig. 4a). Second and third pairs apinnate, with dense lateral ciliation, long, triangular (Fig. 4a); subequal in length, shorter than pinnate pairs.

Notopodial postchaetal lamellae foliaceous and wider on chaetigers 2-6 (Fig. 4b); lamellae larger and subtriangular on chaetiger 2 , largest on chaetigers $3-4$, with blunt tips; progressively decreasing in size on chaetigers 7-12, becoming more rounded on posterior chaetigers of the fragment (Fig. 4c). Ventral and dorsal edges of notopodial and neuropodial lamellae touching on chaetiger 3 (Fig. 4b). Notopodial prechaetal lamellae very short in branchial region (Fig. 4b), inconspicuous thereafter. Dorsal crest or folds absent.

Neuropodial postchaetal lamellae rhomboid on chaetiger 2 (Fig. 4b), third pair rounded and wider than the other neuropodial lamellae (Fig. 4b); rounded and large on chaetiger 4; subsequent neuropodial lamellae triangular and small on far posterior chaetigers (Fig. 4c). Prechaetal lamellae very short, rudimentary throughout. Interparapodial pouches lacking.

All capillaries on anterior chaetigers slender, lacking granulations, and without sheaths; notopodial and neuropodial capillaries of chaetiger 1 arranged in one row, with short, slender chaetae, notopodial chaetae longer. Notopodial capillaries of chaetigers 2-7 arranged in two rows, very long and very acute (Fig. 4d), upper chaetae much longer than lower ones, chaetae curve outward and upward, later becoming shorter. Neuropodial capillaries of chaetigers 2-11 arranged in two rows, very long and very acute (Fig. 4e), with anterior row shorter than posterior row, later becoming one row. Sabre chaetae from chaetiger 11, up to two per fascicle, stout, curved, moderately granulated, without sheaths (Fig. 4f). Neuropodial hooded hooks from chaetiger 12, up to six per fascicle, accompanied by capillaries; hooks with two pairs of teeth above main tooth, first pair of teeth almost the same size as the main tooth, and with large secondary hoods (Fig. 4g); hoods large, almost half the length of the hooks (Fig. $4 \mathrm{~g}$ ), posterior chaetigers from the fragment with long hooded hooks with three pairs of small teeth above the main tooth and a small secondary hood (Fig. 4h). Notopodial hooded hooks not present on holotype.

Posterior region and pygidium not available for examination.

Remarks Prionospio spongicola was synonymized with P. heterobranchia by Foster (1971), because the branchial 


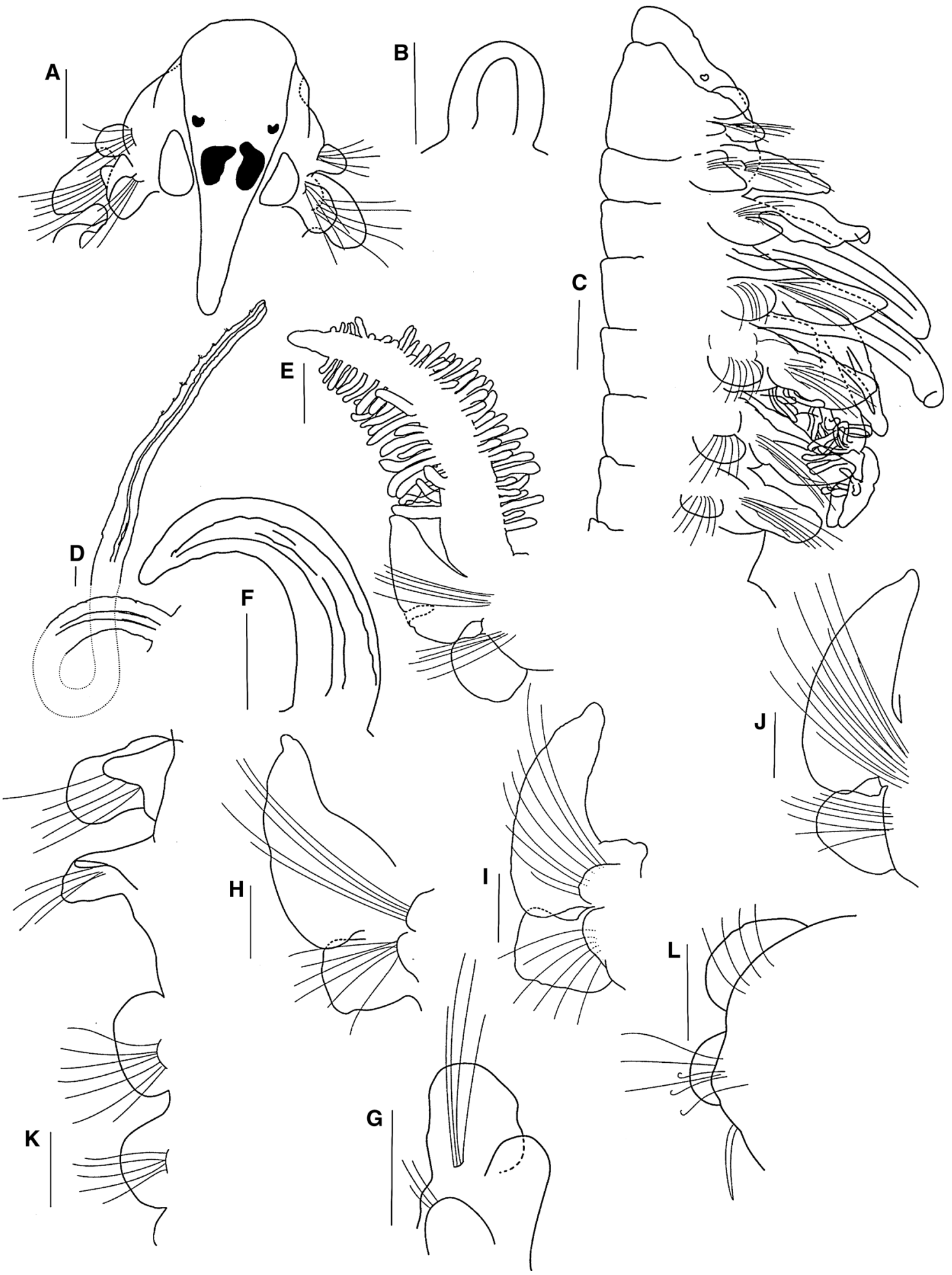

Fig. 5 Prionospio jamaicensis sp. nov., paratype (LACM-AHF POLY 2899): a Anterior region, dorsal view. b Palp in regeneration. c Anterior region, lateral view. d The base and distal part of the palp. e Parapodium and branchia of chaetiger 2. f Branchia of chaetiger 3.

g Parapodium of chaetiger 1. h Parapodium of chaetiger 2 . i Parapodium of chaetiger 3. j Parapodium of chaetiger 4. $\mathbf{k}$ Notopodia of chaetigers 8-11, dorsal view. 1 Parapodium of chaetiger 14. (Scale bars $\mathbf{a}-\mathbf{l} 30 \mu \mathrm{m})$ 

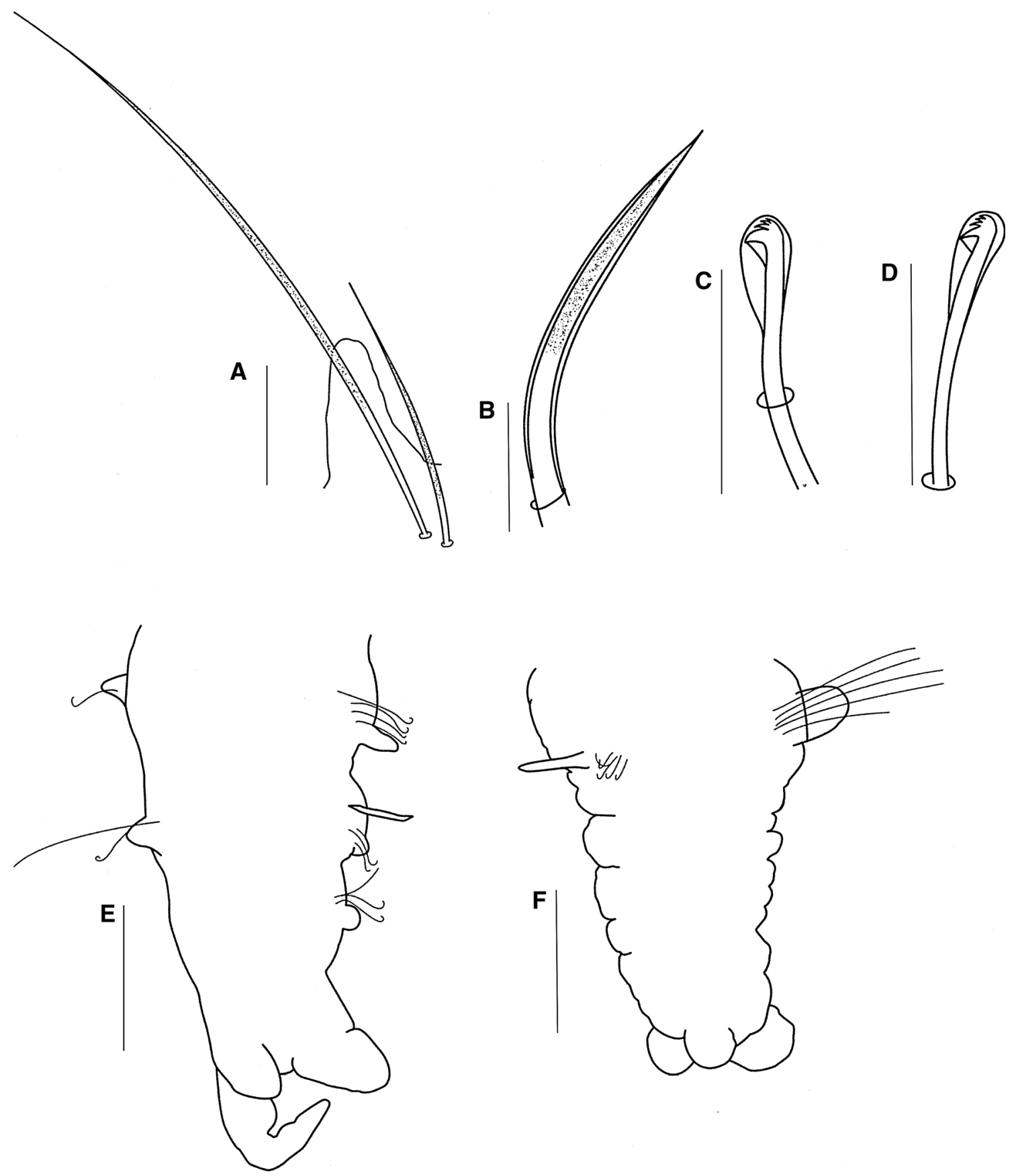

Fig. 6 Prionospio jamaicensis sp. nov., paratype (LACM-AHF POLY 2899): a Notopodial chaetae of middle region of body. b Sabre chaeta. c Neuropodial hooded hook. d Notopodial hooded hook. e Pygidium, ventral view. f Pygidium, dorsal view. (Scale bars e-f $30 \mu \mathrm{m}, \mathbf{a}-\mathbf{d} 5 \mu \mathrm{m})$

pattern conforms to that of the latter species; the third pair of branchiae of the holotype of $P$. spongicola are cirriform rather than pinnate as indicated in the original description. They have fairly long cilia and are similar to those of the second pair.

Examination of the holotype of $P$. spongicola and the holotype and type locality specimens of $P$. heterobranchia in this study has, however, revealed that there are morphological differences between them. P. spongicola differs from $P$. heterobranchia in that the former has a bottleshaped prostomium, a longer peristomium, the size of the first notopodial and neuropodial lamellae is different, the fourth pair of the branchiae is longer and more elongate, the dorsal folds are absent; the notopodial and neuropodial prechaetal lamellae are very short in the branchial region, and all the capillary chaetae are thin, lack granulations and are striated. P. spongicola differs from the other Prionospio species examined in this study in that it has a blunt 
caruncle, the branchiae have fewer and thicker pinnules, the shape of the second and fifth neuropodial postchaetal lamellae is different, the anterior chaetae are very long and acute, sabre chaetae appear from chaetiger 11, the neuropodial hooded hooks have two or three pairs of teeth above the main tooth; the first pair are almost of the same size as the main tooth, and the hoods are large, almost half the length of the hooks on anterior chaetigers. The differences between $P$. spongicola and the other species examined can also be appreciated from the key provided and Table 1 .

Distribution Trinidad: Gasparee Cave on Gasparo Grande Island; in water $20 \mathrm{~m}$ below the surface of limestone terrace with tidal movements, some $200 \mathrm{~m}$ from the shore, which is soft and muddy with a few pieces of decaying wood, $25^{\circ} \mathrm{C}, 11,450 \mathrm{mg} \mathrm{Cl} / 1$ (chiefly from brackish water).

Prionospio jamaicensis sp. nov.

(Figures 5a-1, 6a-f)

Type material North Atlantic, Jamaica, Saint Ann Parish, Saint Ann's Bay, Hofstra University Marine Laboratory Cove, $18.45^{\circ} \mathrm{N}, 77.224^{\circ} \mathrm{W}, 0-10 \mathrm{~m}$, sediment \& detritus from mangrove area, SCUBA, sta. 2G, holotype (LACMAHF POLY 5462), 24 paratypes (LACM-AHF POLY 2899), colls. Rawlinson, K., Bolanos, M., DuPont, A., Allan, A., Dunn, J., Harris, L., 25 May-3 June 2006, LH06492.

Description Holotype complete, $22 \mathrm{~mm}$ long for 67 chaetigers, $0.6 \mathrm{~mm}$ wide. Paratypes mostly posteriorly complete, $\quad 5.5-20.0 \mathrm{~mm}$ long for 44-70 chaetigers, $0.25-0.6 \mathrm{~mm}$ wide. Colour in alcohol opaque white. Prostomium triangular-shaped, rounded on anterior margin (Fig. 5a); posteriorly tapered, with narrow caruncle extending to posterior edge of chaetiger 2 (Fig. 5a). Two pairs of subdermal eyes; arranged in a trapezoid; anterior pair brown, crescent-shaped; posterior pair red to black, oval with a very large inner anterior projection (Fig. 5a). All specimens with a pair of regenerating palps (Fig. 5b), except for one specimen with a pair of long palps, grooved, lacking basal sheaths, extending up to chaetiger 16 (Fig. 5d). Peristomium long, collar-like, surrounding prostomium, fused dorsally with very large rounded notopodial lamellae on chaetiger 1 (Fig. 5c). Neuropodial postchaetal lamellae of chaetiger 1 large, rounded (Fig. $5 \mathrm{~g}$ ).

Five pairs of very long branchiae present on chaetigers 2-6; first and fifth pairs longest, generally first pair longer than fifth, 3 times the size of the notopodial lamellae; pairs 1,4 and 5 with long, dense digitiform pinnules on posterior face, branchiae with short, naked, smooth, distal tips (Fig. 5e); fourth pair with very short naked tips. Distribution of pinnules on these three pairs similar, pinnules numerous, distributed basally to distally. Pairs 2 and 3 cirriform, with little lateral ciliation and blunt tips (Fig. 5c, f); subequal in length, shorter than pinnate pairs, but larger than notopodial lamellae (Fig. 5c).

Notopodial postchaetal lamellae triangular, slender, with blunt tips on chaetigers $2-4$ (Fig. $5 \mathrm{~h}-\mathrm{j}$ ); largest on chaetigers 3-4; lamellae of chaetigers 5-7 subtriangular (Fig. 5c), subsequent notopodial lamellae round, and small on far posterior chaetigers (Fig. 5k, 1). Chaetigers 2-4 overlapping the ventral and dorsal edges of the noto- and neuropodial lamellae (Fig. 5h-j). Notopodial prechaetal lamellae moderate, slender in branchial region, basally fused with notopodial postchaetal lamellae (Fig. 5c), on posterior chaetigers rudimentary (Fig. 51). Dorsal ridges or folds absent.

Neuropodial postchaetal lamellae on chaetigers 2-3 square (Fig. 5h, i), subsequent neuropodial lamellae rounded (Fig. 5c, j) and small on far posterior chaetigers (Fig. 51). Neuropodial prechaetal lamellae very small (Fig. $5 \mathrm{~h}-\mathrm{j}$ ), rudimentary throughout. Interparapodial pouches lacking.

All capillaries on anterior chaetigers unilimbate, thin, without granulations; notopodial and neuropodial capillaries of chaetiger 1 arranged in one row, with short, thin chaetae, notopodial chaetae longer. Notopodial capillaries of chaetigers 2-11 arranged in two rows, anterior row shorter than posterior row; capillaries on middle segments arranged in one row, dorsal chaetae very long and acute and ventral chaetae very short and acute, all with granulations (Fig. 6a); posterior capillaries thin and smooth. Sabre chaetae from chaetiger $12-14$, one or two per parapodium, stout, curved, heavily granulated, with sheaths (Fig. 6b). Neuropodial hooded hooks (Fig. 6c) from chaetigers $12-4$, up to nine per fascicle, accompanied by up to three capillaries. Notopodial hooded hooks (Fig. 6d) from chaetigers $27-48$, up to three per fascicle and accompanied by capillaries; all hooks with three pairs of small teeth above main tooth and small secondary hood; notopodial and neuropodial hooks with large principal hood (Fig. 6c, d).

Pygidium with one long median cirrus and two short lateral lobes (Fig. 6e), and pygidium in regeneration with one wide median lobe and two small rounded lateral lobes (Fig. 6f).

Remarks Prionospio jamaicensis differs from the other Prionospio species described in this study in the shape of the second pair of eyes, having longer notopodial postchaetal lamellae on chaetiger 1 , longer branchiae, chaetigers 2 and 3 with square neuropodial postchaetal lamellae and hooks with three pairs of small teeth above the main tooth. The differences between $P$. jamaicensis from the other species examined can be observed from the key provided and Table 1. 

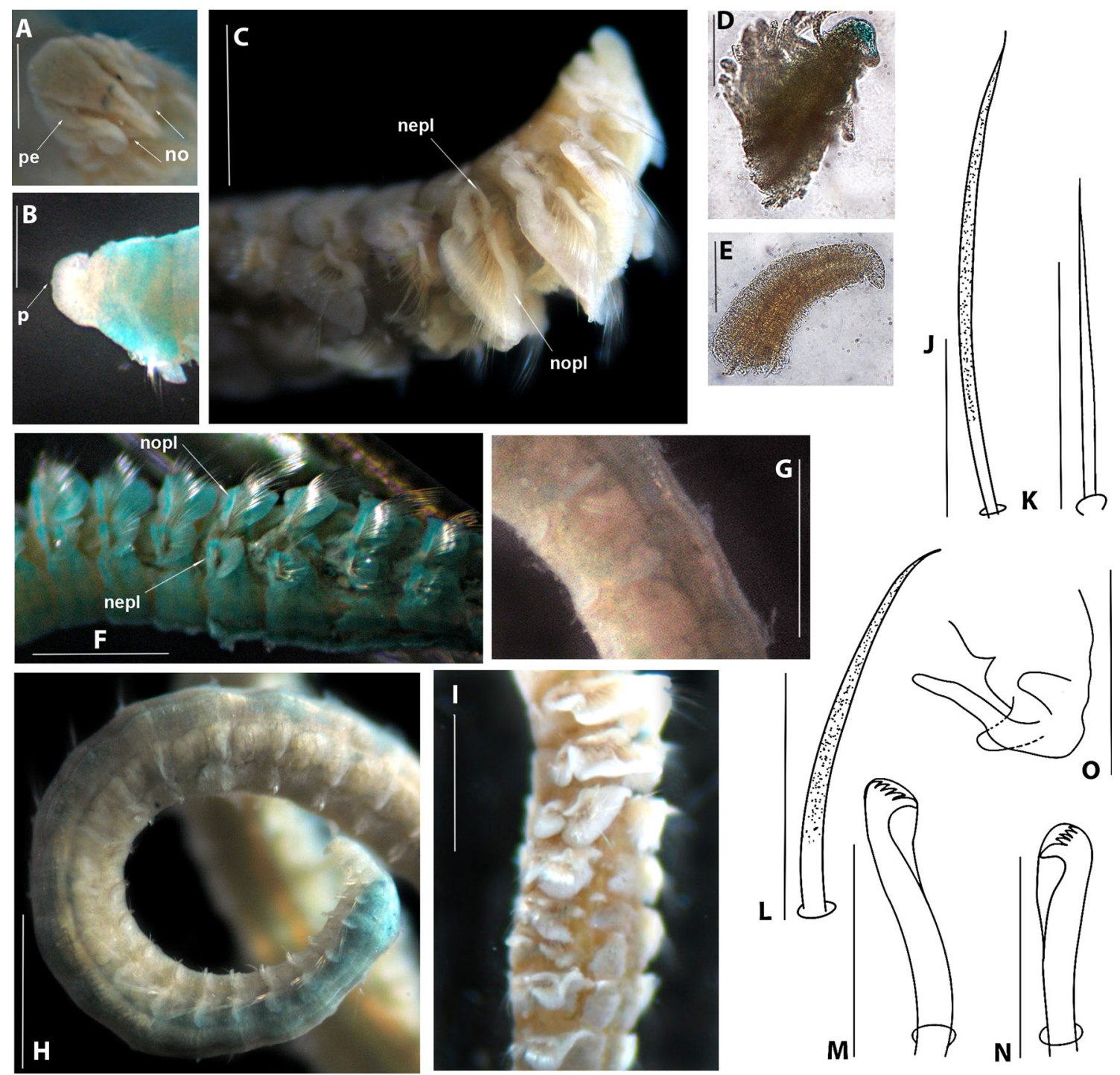

Fig. 7 Prionospio newportensis Reish, 1959 holotype (LACM-AHF POLY 613). a Prostomium, dorsal view. b Prostomium, ventral view. c Anterior region, lateral view. d Pinnate branchia of chaetiger 2 . e Apinnate branchia of chaetiger 3. f Parapodia of chaetigers 4-10. g Middle parapodia. h Posterior region. i Notopodial and neuropodial lamellae of anterior chaetigers with overlapping ventral and dorsal edges. $\mathbf{j}$ Capillary notochaeta of chaetiger 12 . $\mathbf{k}$ Capillary neurochaeta

Etymology The species name is derived from the country of Jamaica and the suffix indicates it lives in that region.

Type locality Caribbean Sea, Jamaica, Saint Ann Parish.

Prionospio newportensis Reish, 1959, new status

Figure $7 \mathrm{a}-\mathrm{o}$

Prionospio heterobranchia newportensis Reish, 1959: 13 , plate 6 , figure 5 .

Material examined North Pacific, USA, California, Orange County, Newport Bay, shallow depths, Sta 53, holotype (LACM-AHF POLY 613), coll. Reish, D. J. of chaetiger 12. I Sabre chaeta of chaetiger 68. m Neuropodial hooded hook of chaetiger 68. n Notopodial hooded hook of chaetiger 68 . o Pygidium, ventral view. Peristomium: pe. Nuchal organs: no. Peak: p. Notopodial prechaetal lamellae: nopl. Neuropodial prechaetal lamellae: nepl (Scale bars a-b $16 \mu \mathrm{m}$, d-e $10 \mu \mathrm{m}, \mathbf{c}, \mathbf{f}, \mathbf{i} 45 \mu \mathrm{m}, \mathbf{g}-$ h $30 \mu \mathrm{m}, \mathbf{j}-\mathbf{n} 5 \mu \mathrm{m}, \mathbf{o} 22 \mu \mathrm{m})$

Redescription A large species; holotype complete, $22.0 \mathrm{~mm}$ long for 91 chaetigers, $1.0 \mathrm{~mm}$ wide. Colour in alcohol opaque white. Prostomium triangular, broadly rounded on anterior margin (Fig. 7a), with small medial peak in ventral region (Fig. 7b), posteriorly tapered. Caruncle long, narrow, extending to anterior edge of chaetiger 3, with large triangular nuchal organ on either side (Fig. 7a). Two pairs of dark eyes arranged in a trapezoid; anterior pair small and round; posterior pair crescentshaped (Fig. 7a). Palps lost. Peristomium short, collar-like, surrounding prostomium, partly fused dorsally with large rounded notopodial lamellae on chaetiger 1 (Fig. 7a). 
Neuropodial postchaetal lamellae of chaetiger 1 rounded and small (Fig. 7c), much smaller than half the size of the notopodial lamella.

Five pairs of short, thick branchiae present on chaetigers 2-6; first pair longest, progressively decreasing in size. All branchiae with short tapered tips. Pairs 1,4 and 5 with long, dense digitiform pinnules on posterior face (Fig. 7d), and short, naked, smooth, distal tips (Fig. 7d). Pairs 2 and 3 apinnate, sparsely ciliated, triangular (Fig. 7e); equal in size and length to the notopodial lamellae.

Notopodial postchaetal lamellae foliaceous (Fig. 7c); lamellae large and subtriangular on chaetiger 2, largest on chaetigers 3 and 4 with prolonged tips directed upwards (Fig. 7c), smaller and more rounded on subsequent chaetigers (Fig. 7f). Lamellae gradually becoming smaller, rounder and more ventrally directed by chaetiger 13 (Fig. 7g). Lamellae of posterior chaetigers rounded, but more dorsally directed (Fig. 7h). Notopodial and neuropodial lamellae of chaetigers $2-8$ with overlapping ventral and dorsal edges (Fig. 7c, i). Notopodial prechaetal lamellae very conspicuous on chaetigers $2-7$, basally fused with notopodial postchaetal lamellae (Fig. 7c), smaller on chaetigers 8-12 (Fig. 7f) and rudimentary from chaetiger 13. Dorsal crest or folds absent.

Neuropodial postchaetal lamellae large and rounded on chaetiger 2, subtriangular on chaetiger 3 (Fig. 7c), oval on chaetiger 4 , and subsequently rounded (Fig. 7f); small on far posterior chaetigers (Fig. $7 \mathrm{~g}, \mathrm{~h}$ ). Prechaetal lamellae large (Fig. 7c-f), progressively decreasing in size on subsequent chaetigers. Interparapodial pouches lacking.

Notopodial capillaries of chaetiger 1, short, thin, smooth, arranged in a row; from chaetiger 2 arranged in two rows, the anterior row shorter and without granulations, the posterior row longer, granulated, with long capillary tips (Fig. 7j); chaetae of middle notopodia arranged in one row with dorsal chaetae very long and ventral chaetae short; posterior notopodia with thinner, shorter chaetae than middle notopodia. All neuropodial capillaries thin and without granulations, with long capillary tips (Fig. 7k). Sabre chaetae from chaetiger 16, up to two per fascicle, stout, with slightly curved tips, distinctly granulated, without sheaths (Fig. 7l). Neuropodial hooded hooks from chaetiger 14 (Fig. $7 \mathrm{~m}$ ), up to 11 per fascicle, accompanied by up to four capillaries. Notopodial hooded hooks (Fig. 7n) from chaetiger 54, up to four per fascicle, accompanied by up to 10 capillaries; all hooks with four pairs of small teeth above main tooth, without secondary hood; hooks with a curved main tooth, notopodial hooks with a thicker tooth (Fig. 7n).

Pygidium with one long median cirrus and two short lateral lobes (Fig. 7o).
Remarks Reish (1959) briefly described Prionospio (Prionospio) newportensis as a new subspecies from California and compared his specimens with the descriptions of P. heterobranchia Moore, 1907 and $P$. h. texana Hartman, 1951. Reish (1959) separated these three taxa as follows: Prionospio heterobranchia: one pair of eyes, neuropodial hooks from segment 15 and notopodial hooks from segment $40 ; P$. h. texana: two pairs of eyes, neuropodial hooks from segment 12 and notopodial hooks from segment $35 ; P$. h. newportensis: two pairs of eyes, neuropodial hooks from segment 14 and notopodial hooks from segments 42 to 55. Later, Foster (1971) placed these new subspecies in synonymy with $P$. heterobranchia because of the variation she observed in the morphologies of different specimens within a single sample, including that of the stem species and both subspecies, and because no other taxonomic differences could be found upon examination of the type material. In spite of this, Fauchald (1972) retained the subspecies $P$. h. texana and $P$. $h$. newportensis. Maciolek (1985), however, preferred to maintain the synonymy because of the evidence presented by Foster (1971), although she did not reexamine the specimens.

The reexamination and redescription of the holotypes of $P$. newportensis and $P$. heterobranchia in this study, in disagreement with Foster (1971), have led to the conclusion that $P$. newportensis definitely represents a distinct species and can be separated from $P$. heterobranchia on the basis of several characters.

Prionospio newportensis Reish, 1959 differs from $P$. heterobranchia in the shape and size of the eyes, the size of the first notopodial lamellae, the complete absence of dorsal ridges or folds and the shape of the neuropodial lamellae. In addition, in P. newportensis, the fourth pair of branchiae is elongate, all capillaries on the anterior chaetae are smooth and notopodial hooded hooks are present from chaetiger 54. P. newportensis differs from the other Prionospio species examined in this study in having a small medial peak on the anterior margin of the prostomium, a longer caruncle, shorter and thicker branchiae, the ventral and dorsal edges of the noto- and neuropodial lamellae overlapping on chaetigers $6-8$, subtriangular lamellae on chaetiger 3 , sabre chaetae from chaetiger 16 and all hooks without secondary hoods. The differences between $P$. newportensis and the other Prionospio species can also be appreciated from the key provided and Table 1 .

Distribution Newport Bay, California, from shallow depths.

Prionospio rosariae sp. nov.

Figures $8 \mathrm{a}-\mathrm{j}, 9 \mathrm{a}-\mathrm{f}$ 


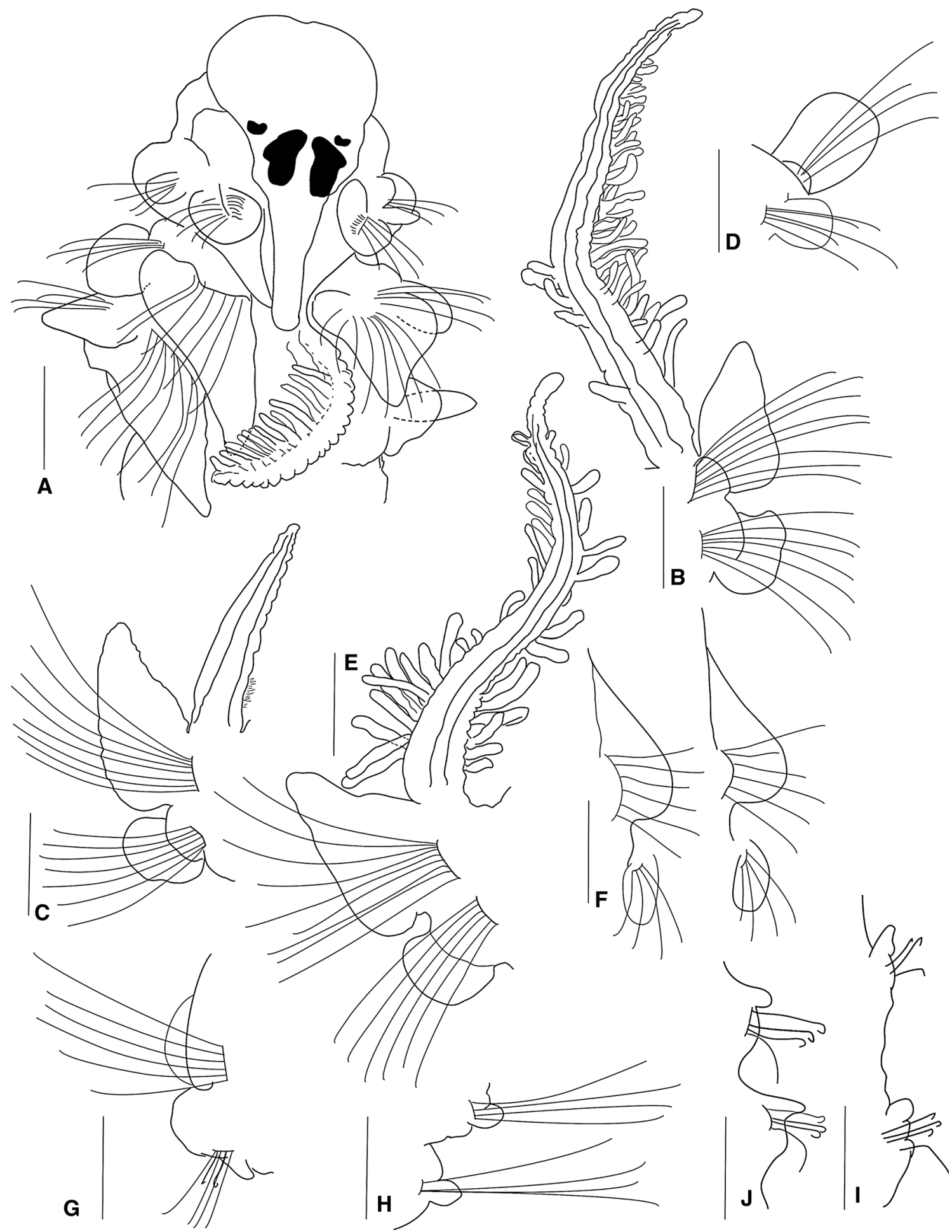

Fig. 8 Prionsopio rosariae sp. nov., holotype (NMNH 1187917), a Anterior region, dorsal view. Paratype (ECOSUR-000): b Parapodium and branchia of chaetiger 2. $\mathbf{c}$ Parapodium and branchia of chaetiger 3 . d Parapodium of chaetiger 1. e Parapodium and branchia of chaetiger 6 . f Parapodia of chaetigers 11-12. g Parapodium of chaetiger 14. hi middle parapodium. j Posterior parapodia. (Scale bars $\mathbf{a}-\mathbf{j} 50 \mu \mathrm{m}$ )
Material examined Caribbean Sea: Chetumal Bay, Quintana Roo, coll. Delgado-Blas, V.H.: sta. 4CN3, $36^{\circ} 34^{\prime} 60^{\prime \prime} \mathrm{N}, 20^{\circ} 44^{\prime} 74^{\prime \prime} \mathrm{W}, 0.5 \mathrm{~m}, 29.6^{\circ} \mathrm{C}, 21 \%$, $8.16 \mathrm{pH}$,
$2.96 \mathrm{mg} / \mathrm{l} \mathrm{O}, 14$ specimens (ECOSUR-P2649), June 12, 2005; sta. 4CN4, 1 specimen (ECOSUR-P2650); sta. $4 \mathrm{BN} 1, \quad 0.39 \mathrm{~m}, \quad 30.6^{\circ} \mathrm{C}, \quad 17 \%, 8.0 \mathrm{pH}, 4 \mathrm{mg} / \mathrm{l} \mathrm{O}, 1$ 
Fig. 9 Prionsopio rosariae sp. nov., holotype (NMNH 1187917): a Capillary notochaeta of anterior chaetiger. b Capillary neurochaeta of anterior chaetiger. c Sabre chaeta. d Neuropodial hooded hook. e Notopodial hooded hooks. f Pygidium, ventral view. (Scale bars $\mathbf{f} 50 \mu \mathrm{m}, \mathbf{a}-\mathbf{e} 5 \mu \mathrm{m}$ )
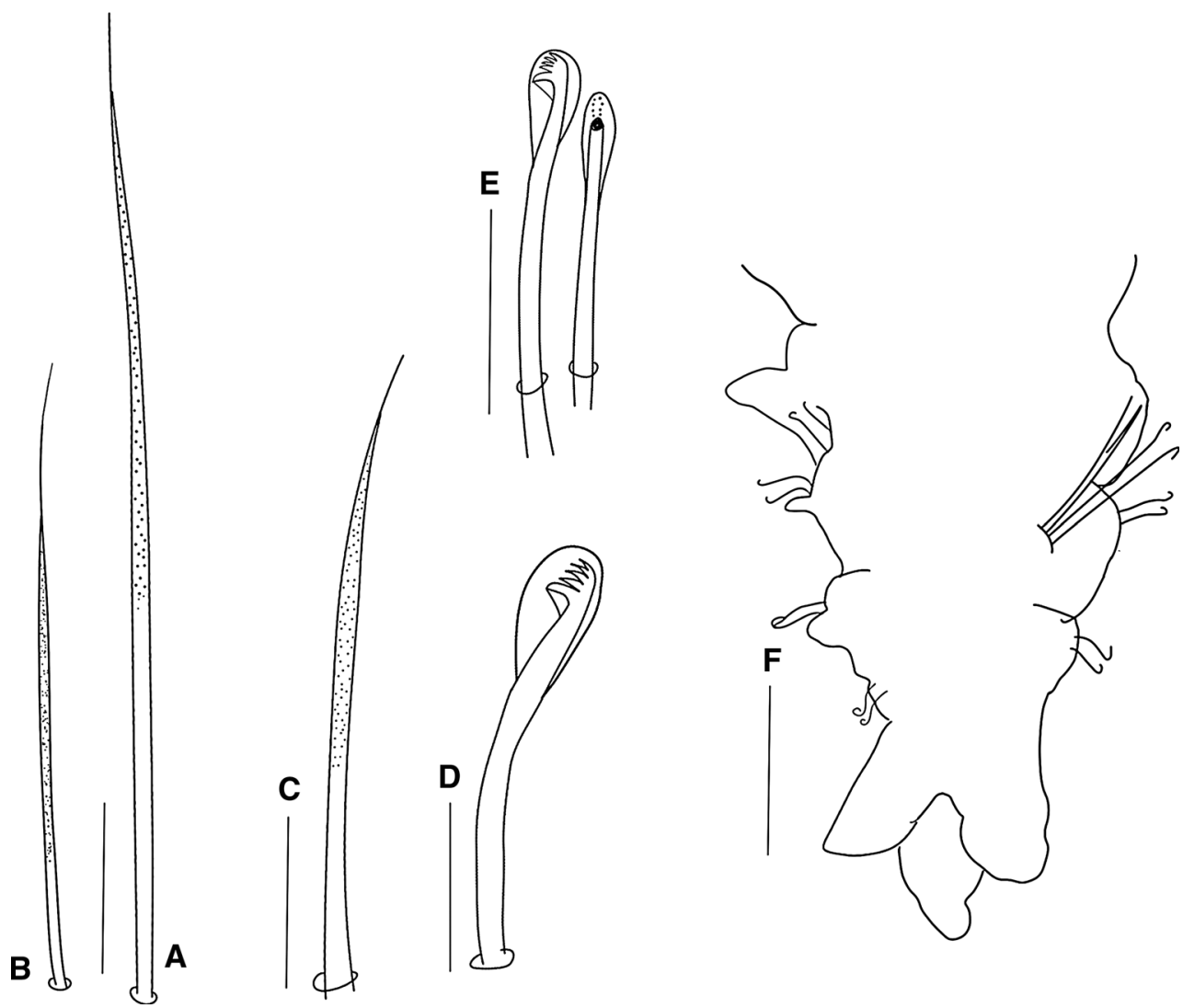

specimen (ECOSUR-P2651); sta. 4BN4, 1 specimen (ECOSUR-P2652); June 12, 2005, sta. 5BN3, 36 $37^{\prime} 74^{\prime \prime} \mathrm{N}$, $20^{\circ} 45^{\prime} 12^{\prime \prime} \mathrm{W}, 5.58 \mathrm{~m}, 30^{\circ} \mathrm{C}, 21.6 \%$, $8.16 \mathrm{pH}, 4 \mathrm{mg} / \mathrm{l} \mathrm{O}, 2$ paratypes (ECOSUR-0153); June 12, 2005, sta. 5AN4, $36^{\circ} 36^{\prime} 84^{\prime \prime} \mathrm{N}, 20^{\circ} 45^{\prime} 75^{\prime \prime} \mathrm{W}, 0.6 \mathrm{~m}, 30^{\circ} \mathrm{C}, 21 \%$, $8.14 \mathrm{pH}$, $3.4 \mathrm{mg} / \mathrm{l} \mathrm{O,} 9$ paratypes (ECOSUR-0154); June 12, 2005, sta. $4 \mathrm{CN} 2, \quad 36^{\circ} 38^{\prime} 93^{\prime \prime} \mathrm{N}, 20^{\circ} 44^{\prime} 89^{\prime \prime} \mathrm{W}, 0.5 \mathrm{~m}, 29.5^{\circ} \mathrm{C}$, $21 \%, 8.16 \mathrm{pH}, 2.96 \mathrm{mg} / \mathrm{l} \mathrm{O}, 3$ specimens (ECOSURP2653); June 12, 2005, sta. $6 \mathrm{BN} 3, \quad 36^{\circ} 41^{\prime} 59^{\prime \prime} \mathrm{N}$, $20^{\circ} 45^{\prime} 36^{\prime \prime} \mathrm{W}, 0.48 \mathrm{~m}, 30.8^{\circ} \mathrm{C}, 21.5 \%$, $8.14 \mathrm{pH}, 5.74 \mathrm{mg} / \mathrm{l}$ O, 2 specimens (ECOSUR-P2654); June 12, 2005, sta. $6 \mathrm{AN} 3,36^{\circ} 41^{\prime} 43^{\prime \prime} \mathrm{N}, 20^{\circ} 45^{\prime} 59^{\prime \prime} \mathrm{W}, 0.30 \mathrm{~m}, 31.6^{\circ} \mathrm{C}, 21 \%$, $8.17 \mathrm{pH}, 6.17 \mathrm{mg} / \mathrm{l} \mathrm{O}, 1$ specimen (ECOSUR-P2655); sta. 6AN4, 2 specimens (ECOSUR-P2656); June 12, 2005, sta. 6AN1 $0.30 \mathrm{~m}, 31.6^{\circ} \mathrm{C}, 21 \%, 8.17 \mathrm{pH}, 6.17 \mathrm{mg} / \mathrm{l} \mathrm{O}, \mathbf{1}$ paratype (ECOSUR-0155); February 4, 2006, sta. 7BN4, $36^{\circ} 44^{\prime} 30^{\prime \prime} \mathrm{N}, 20^{\circ} 45^{\prime} 23^{\prime \prime} \mathrm{W}, 2 \mathrm{~m}, 31^{\circ} \mathrm{C}, 12 \%, 8.14 \mathrm{pH}$, $6.08 \mathrm{mg} / \mathrm{l} \mathrm{O}$, holotype (NMNH 1187917); sta. 7BN4, 1 paratype (ECOSUR-0156); June 12, 2005, sta. 7CN2, $36^{\circ} 45^{\prime} 09^{\prime \prime} \mathrm{N}, 20^{\circ} 45^{\prime} 85^{\prime \prime} \mathrm{W}, 1.52 \mathrm{~m}, 30^{\circ} \mathrm{C}, 22 \%$, $8.18 \mathrm{pH}$, $6.56 \mathrm{mg} / \mathrm{l} \mathrm{O}, 1$ paratype (ECOSUR-0157); 7CN1, 2 specimens (ECOSUR-P2657); sta. 8AN2, $36^{\circ} 44^{\prime} 51^{\prime \prime} \mathrm{N}$, $20^{\circ} 45^{\prime} 43^{\prime \prime} \mathrm{W}, 0.23 \mathrm{~m}, 32^{\circ} \mathrm{C}, 21 \%$, $8.17 \mathrm{pH}, 7.15 \mathrm{mg} / \mathrm{l} \mathrm{O}, 1$ paratype (ECOSUR-0158); sta. 9CN4, no date given, 1 specimen (ECOSUR-P2658); June 12, 2005, sta. 10BN1, $36^{\circ} 52^{\prime} 30^{\prime \prime} \mathrm{N}, 20^{\circ} 46^{\prime} 98^{\prime \prime} \mathrm{W}, 0.67 \mathrm{~m}, 30^{\circ} \mathrm{C}, 21.7 \%$, $8.0 \mathrm{pH}$,
$5.79 \mathrm{mg} / \mathrm{l} \mathrm{O}, 1$ paratype (ECOSUR-0159); June 12, 2005, sta. $10 \mathrm{BN} 3,36^{\circ} 52^{\prime} 30^{\prime \prime} \mathrm{N}, 20^{\circ} 46^{\prime} 98^{\prime \prime} \mathrm{W}, 0.67 \mathrm{~m}, 30.5^{\circ} \mathrm{C}$, $21.7 \%, 8.0 \mathrm{pH}, 5.79 \mathrm{mg} / \mathrm{l} \mathrm{O}, 1$ specimen (ECOSURP2659); June 12, 2005, sta. 10AN4, 36 $51^{\prime} 73^{\prime \prime} \mathrm{N}$, $20^{\circ} 47^{\prime} 47^{\prime \prime} \mathrm{W}, 0.25 \mathrm{~m}, 31^{\circ} \mathrm{C}, 22 \%$, $7.97 \mathrm{pH}, 5.25 \mathrm{mg} / \mathrm{l} \mathrm{O}, 1$ specimen (ECOSUR-P2660); June 12, 2005, sta. 10CN2, $36^{\circ} 53^{\prime} 64^{\prime \prime} \mathrm{N}, 20^{\circ} 46^{\prime} 91^{\prime \prime} \mathrm{W}, 1.48 \mathrm{~m}, 30.5^{\circ} \mathrm{C}, 21.8 \%$ \% 8.06 $\mathrm{pH}, 6.45 \mathrm{mg} / \mathrm{l} \mathrm{O}, 1$ specimen (ECOSUR-P2661); June 12, 2005 , sta. $10 \mathrm{CN} 4,36^{\circ} 53^{\prime} 64^{\prime \prime} \mathrm{N}, 20^{\circ} 46^{\prime} 91^{\prime \prime} \mathrm{W}, 1.48 \mathrm{~m}$, $30^{\circ} \mathrm{C}, 21 \%, 8.0 \mathrm{pH}, 6.45 \mathrm{mg} / \mathrm{l} \mathrm{O}, 16$ paratypes (ECOSUR-0160); 10BN1, 36 $52^{\prime} 30^{\prime \prime} \mathrm{N}, 20^{\circ} 46^{\prime} 98^{\prime \prime} \mathrm{W}, 0.67 \mathrm{~m}$, $30.5^{\circ} \mathrm{C}, 21.7 \%, 8.0 \mathrm{pH}, 5.79 \mathrm{mg} / \mathrm{l} \quad \mathrm{O}, 2$ paratypes (ECOSUR-0161); sta. 10BN2, 1 specimen (ECOSURP2662); sta. 10CN3, 1 specimen (ECOSUR-P2663); sta. 11AN2, no date given, 1 specimen (ECOSUR-P2664).

Description A small species; holotype complete, $6 \mathrm{~mm}$ long for 56 chaetigers, $0.5 \mathrm{~mm}$ wide. Paratypes $4.0-9.0 \mathrm{~mm}$ long, $0.4-0.7 \mathrm{~mm}$ wide, with $38-65$ chaetigers. Colour in alcohol opaque white. Prostomium triangular, broadly rounded anteriorly with a slight central notch (Fig. 8a); posteriorly tapered, with narrow caruncle extending to the posterior edge of chaetiger 2 (Fig. 8a). Two pairs of redbrown to black subdermal eyes; arranged in a trapezoid; anterior pairs crescent-shaped; posterior pairs arranged just anterior to the caruncle, T-shaped (Fig. 8a). Palps lost. 
Peristomium short, collar-like, surrounding prostomium, fused dorsally with large rounded notopodial lamellae of chaetiger 1 (Fig. 8a, d), which are twice the size of the neuropodial lamellae. Neuropodial postchaetal lamellae of chaetiger 1 large, rounded (Fig. 8d).

Five pairs of very long, thin branchiae present on chaetigers 2-6; first and fifth pairs of equal size, twice the length of the other pairs; second, third and fourth pairs of equal size. Pairs 1, 4 and 5 with long and dense digitiform pinnules on lateral face, with short, naked and slightly wrinkled distal tips (Fig. 8b, e). Distribution of pinnules on these three pairs similar, larger basally, but less numerous on the fourth pair. Pairs 2 and 3 apinnate, laterally densely ciliated, thin, subtriangular; branchiae longer than the notopodial lamellae (Fig. 8c).

Notopodial postchaetal lamellae foliaceous, subtriangular (Fig. 8a-c, e); largest on chaetigers 2-6, with blunt tip; progressively decreasing in size on chaetigers $7-12$, and becoming more rounded (Fig. 8f-g). Middle chaetigers with subtriangular lamellae (Fig. 8h-i), becoming smaller and more rounded on posterior chaetigers (Fig. 8j). Ventral and dorsal edges of anterior notopodial and neuropodial lamellae not overlapping or even touching. Notopodial prechaetal lamellae short in branchial region (Fig. 8b, c, e) inconspicuous thereafter. Dorsal crest or folds absent.

Neuropodial postchaetal lamellae of chaetigers 2 and 3 becoming progressively larger; neuropodial lamellae of chaetiger 2 subrectangular, with dorsally directed process, the lower corner rounded (Fig. 8b); lamellae rounded on chaetigers 3-6 (Fig. 8c, e); progressively decreasing in size from chaetigers 11-12 and becoming even more rounded (Fig. 8f). Middle and posterior chaetigers with short, subtriangular lamellae (Fig. 8g-j). Prechaetal lamellae very short, rudimentary throughout. Interparapodial pouches lacking.

All capillaries slender on anterior chaetigers, granulated, without sheaths, with very long capillary tips (Fig. 9a, b); notopodial and neuropodial capillaries of chaetiger 1 arranged in one row; chaetae short and slender, but notopodial chaetae longer. Notopodial capillaries (Fig. 9a) of chaetigers 2-24 and neuropodial capillaries (Fig. 9b) of chaetigers 2-16 arranged in two rows with anterior row shorter than posterior row; posterior notopodia with one row of chaetae, chaetae thinner and longer than on anterior notopodia; posterior neuropodia with one or two shorter, slender chaetae. Sabre chaetae from chaetiger 12-13, one or two per fascicle, stout, distally granulated and with long tips (Fig. 9c). Neuropodial hooded hooks (Fig. 9d) from chaetigers $12-14$, up to 10 per fascicle, accompanied by up to four capillaries. Notopodial hooded hooks (Fig. 9e) from chaetigers $23-39$, up to five per fascicle; all hooks with four pairs of small teeth above main tooth and small secondary hood (Fig. 9d-e).

Pygidium with one long median cirrus and two short lateral lobes (Fig. 9f).

Remarks Prionospio rosariae differs from the other Prionospio species reported here in that it is a small species, the prostomium has a central notch on the anterior margin, the second pair of eyes is T-shaped, the branchiae have short, naked and slightly wrinkled distal tips, the neuropodia on chaetiger 2 have a dorsally directed process with the lower corner rounded, and the ventral and dorsal edges of the notopodial and neuropodial lamellae do not overlap. Prionospio rosariae is similar to $P$. spongicola in that the notopodial prechaetal lamellae are short in the branchial region. However, it differs in the shape of the prostomium, the form of the neuropodial postchaetal lamellae of chaetiger 2 and in the structure of the hooded hooks and capillaries. The differences between $P$. rosariae and the other species examined can also be appreciated from the key provided and Table 1.

Etymology This species is dedicated to Maria del Rosario Martínez Hernández, my wife, for her unconditional support and company.

Type locality Chetumal Bay, Caribbean Sea.

Key to known species of Prionospio with five pairs of branchiae

1. Dorsal crests or folds on several postbranchial 2 chaetigers

Dorsal crests or folds absent

2. Prostomium triangular-shaped; short peristomium fused with a pair of small notopodial lamellae; the fourth pair of branchiae pinnate with triangular central stems; anterior neuropodial prechaetal lamellae large; anterior chaetae always granulated and capillaries slightly striated

Prostomium bottle-shaped; moderately sized peristomium fused with a pair of large notopodial lamellae; the fourth pairs of branchiae pinnate with elongated central stems; anterior neuropodial prechaetal lamellae very short; anterior chaetae not granulated or striated

3. Neuropodial postchaetal lamellae on chaetiger 4

2 rounded, square or rhomboid; anterior notopodial and neuropodial lamellae overlapping or touching

Neuropodial postchaetal lamellae on chaetiger 2 subrectangular, with dorsally directed process, the lower corners rounded; anterior notopodial and neuropodial lamellae separate

4. Prostomium with a small medial peak on anterior margin; neuropodial lamellae on chaetiger 3 subtriangular; anterior neuropodial prechaetal lamellae large; ventral and dorsal edges of the notopodial and neuropodial lamellae overlapping on chaetigers 2-8; hooks without secondary hoods
3

$P$.

heterobranchia

P. caribensis sp. nov.

P. rosariae sp. nov.

P. newportensis 
continued

Prostomium without small medial peak; neuropodial lamellae on chaetiger 3 rounded or square; anterior neuropodial prechaetal lamellae short; ventral and dorsal edges of the notopodial and neuropodial lamellae overlapping or touching on chaetigers $2-4$; hooks with secondary hoods

5. Prostomium anteriorly rounded; peristomium long; neuropodial lamellae on chaetiger 2 square or rhomboid; anterior notopodial chaetae not granulated; hooded hooks with 2-3 pairs of teeth

Prostomium anteriorly truncated; peristomium $P$. texana short; neuropodial lamellae on chaetigers 2-3 rounded; anterior notopodial chaetae granulated; hooded hooks with 4 pairs of teeth

6. Neuropodial lamellae rhomboid on chaetiger $2 \quad P$. spongicola and rounded on chaetiger 3 ; sabre chaetae without sheaths; hooded hooks with 2-3 pairs of teeth

Neuropodial lamellae on chaetigers 2-3 square; $\boldsymbol{P}$. jamaicensis sabre chaetae with sheaths; hooded hooks with 3 sp. nov. pairs of teeth

Acknowledgments I would like to thank Emma Sherlock (BMNH), Linda Ward (USNM) and Karen Osborn (USNM) for their generous support during a research visit to their museums. I would also like to thank Leslie Harris (LACMNH-AHF) and Paul Callomon (ANSP) for kindly providing the material. This study was supported in part by the Division de Ciencias e Ingeniería of the Universidad de Quintana Roo and PROMEP (Programa para el mejoramiento del profesorado). I also wish to thank Humberto Bahena Basave for his help in taking some pictures. Also, I thank Luis F. Carrera-Parra and Sergio I. Salazar-Vallejo for giving me space in their laboratory during my sabbatical year and conclude with this work. Finally, I thank two anonymous referees for their helpful comments.

\section{References}

Blake JA (1996) Family Spionidae Grube, 1850, including a review of the genera and species from California and a revision of the genus Polydora Bosc, 1802. In: Hilbig B, Scott PH, Blake JA (eds) The Annelida, Part 3. Polychaeta: Orbiniidae To Cossuridae, Taxonomic atlas of the benthic fauna of the santa maria basin and the western santa barbara channel, vol 6. Santa Barbara Museum Natural History, Santa Barbara, pp 81-223

Blake JA, Kudenov JD (1978) The Spionidae (Polychaeta) from southeastern Australia and adjacent areas, with a revision of the genera. Mem Natl Mus Vict 39:171-280

Fauchald K (1972) Benthic polychaetous annelids from deep water off western Mexico and adjacent areas in the eastern Pacific Ocean. Allan Hancock Monogr Mar Biol 7:1-572

Foster N (1971) Spionidae (Polychaeta) of the Gulf of Mexico and the Caribbean Sea. Studies on the Fauna of Curaçao and other Caribbean Islands. Stud Fauna Curaçao Caribb Islands 36:1-183

Hartman O (1951) The littoral marine annelids of the Gulf of Mexico. Publ Inst Mar Sci 2:3-58

Maciolek NJ (1985) A revision of the genus Prionospio Malmgren, with special emphasis on species from the Atlantic Ocean, and new records of species belonging to the genera Apoprionospio Foster and Paraprionospio Caullery (Polychaeta, Annelida, Spionidae). Zool J Linn Soc 84:325-383

Malmgren AJ (1867) Annulata polychaeta Spetsbergiae, Groenlandiae, Islandiae et Scandinaviae hactenus cognita. Öfvers $\mathrm{K}$ VetenskAkad Förh Stockh 24:127-235

Moore JP (1907) Description of new species of spioniform annelids. Proc Acad Natl Sci Phila 59:195-207

Reish DJ (1959) New species of Spionidae (Annelida: Polychaeta) from southern California. Bull South Calif Acad Sci 58:11-16

Sigvaldadóttir E (1997) A new species of Prionospio (Polychaeta: Spionidae) from the Cape d'aguilar marine reserve, Hong Kong. In: Morton B (ed) The Marine Flora and Fauna of Hong Kong and Southern China IV. Proceedings of the eighth international marine biological workshop, Hong Kong, 2-20 April 1995. Hong Kong University Press. pp 53-61

Sigvaldadóttir E, Mackie ASY (1993) Prionospio steenstrupi, P. fallax and P. dubia (Polychaeta, Spionidae): re-evaluation of identity and status. Sarsia 78:203-219

Wesenberg-Lund E (1958) Lesser Antillean polychaetes, chiefly from brackish water, with a survey and a bibliography of fresh and brackish-water polychaetes. Stud Fauna Curaçao Caribb Islands $8: 1-41$

Wilson RS (1990) Prionospio and Paraprionospio (Polychaeta: Spionidae) from southern Australia. Mem Mus Vict 50:243-274

Zhou J, Li X (2009) Report of Prionospio complex (Annelida: Polychaeta: Spionidae) from China's waters, with description of a new species. Acta Oceanol Sin 1:116-127 